\title{
A Simple Route to the Complexation of Lutein with Reduced Graphene Oxide Nanocarriers and Antioxidant Protection Against Blue Light
}

\author{
Seon Yeong Chae' \\ Min Chan Shin ${ }^{2}$ \\ Sangheon Jeon ${ }^{2}$ \\ Moon Sung Kang ${ }^{2}$ \\ Dong-Wook Han (D) $^{2}$ \\ Suck Won Hong $\mathbb{( D}^{2}$ \\ 'Research Center for Dielectric and \\ Advanced Matter Physics, Pusan National \\ University, Busan, 4624I, Republic of Korea; \\ ${ }^{2}$ Department of Cogno-Mechatronics \\ Engineering, Department of Optics and \\ Mechatronics Engineering, College of \\ Nanoscience and Nanotechnology, Pusan \\ National University, Busan, 4624I, Republic \\ of Korea
}

Background: The excellent physicochemical properties of graphene-based materials, including graphene oxide (GO) and reduced GO (rGO), offer significant technological potential as multifunctional nanomaterials in biomedical fields. Lutein is a type of carotenoid that forms human macular pigments in the retina, where it inhibits harmful blue light and contributes to the strengthening of the antioxidant defense of retinal pigment epithelium cells.

Methods: Synthesis of the Lutein-rGO ( $\mathrm{Lu}-\mathrm{rGO})$ complex was carried out for the optimized concentration. Then characterization of material was analyzed through ultraviolet-visible spectrophotometer (UV-Vis spectra), Fourier-transform infrared spectroscopy (FT-IR), Raman spectroscopy, x-ray photoelectron spectroscopy (XPS), transmission electron microscopy (TEM). Antioxidant activity of Lu-rGO complex was measured by 2,2'-azino-bis (3-ethylbenzothiazoline-6-sulfonic acid) (ABTS), 2.2-diphenyl-1-picrylhydrazyl (DPPH), glutathione (GSH) oxidation assay. Then, oxidative stress induction by blue light and analyzed intracellular reactive oxygen species (ROS).

Results and Conclusion: Based on the FT-IR measurement, the reduction efficiency defined by area was found to be $87.3 \%$, the $\mathrm{I}_{\mathrm{D}} / \mathrm{I}_{\mathrm{G}}$ ratio of 0.98 demonstrated by the $\mathrm{Lu}-\mathrm{rGO}$ complex in the Raman spectrum was slightly higher than that of the original GO. The exhibited significant decrease in the peak intensities of the oxygen functional groups of the XPS spectra of the LurGO complex was observed compared with the GO. In the TEM image for the Lu-rGO complex, folded and wrinkled nanostructures over the lutein-covered rGO surface were evidenced by tight molecular binding. The Lu-rGO complex provided superior DPPH and ABTS radical scavenging activity than GO and lutein alone, and the oxidation of GSH was suppressed. It was confirmed that the content of intracellular ROS and lysosomes, increased by blue light, was reduced after treatment with the Lu-rGO complex on ARPE-19 cells. In summary, graphene-based nanocarriers could function as preventative antioxidants during photochemical ROS generation based on the mechanism of antioxidant action.

Keywords: reduced graphene oxide, lutein, antioxidant, blue light, nanocarrier

\section{Introduction}

Lutein is a type of xanthophyll and is one of the most common carotenoids, which are a group of fat-soluble yellow pigments found primarily in fruits, green leafy vegetables, and marigold flowers. ${ }^{1}$ Because it has the ability to prevent chronic diseases, including age-related macular degeneration (AMD), cataracts, and other disorders of the eye, lutein has become the focus of considerable interest., Additionally, the powerful antioxidant properties of lutein have raised its profile as an important functional compound, eg, the pigment protects cells against
Correspondence: Suck Won Hong

Email swhong@pusan.ac.kr 
Graphical Abstract

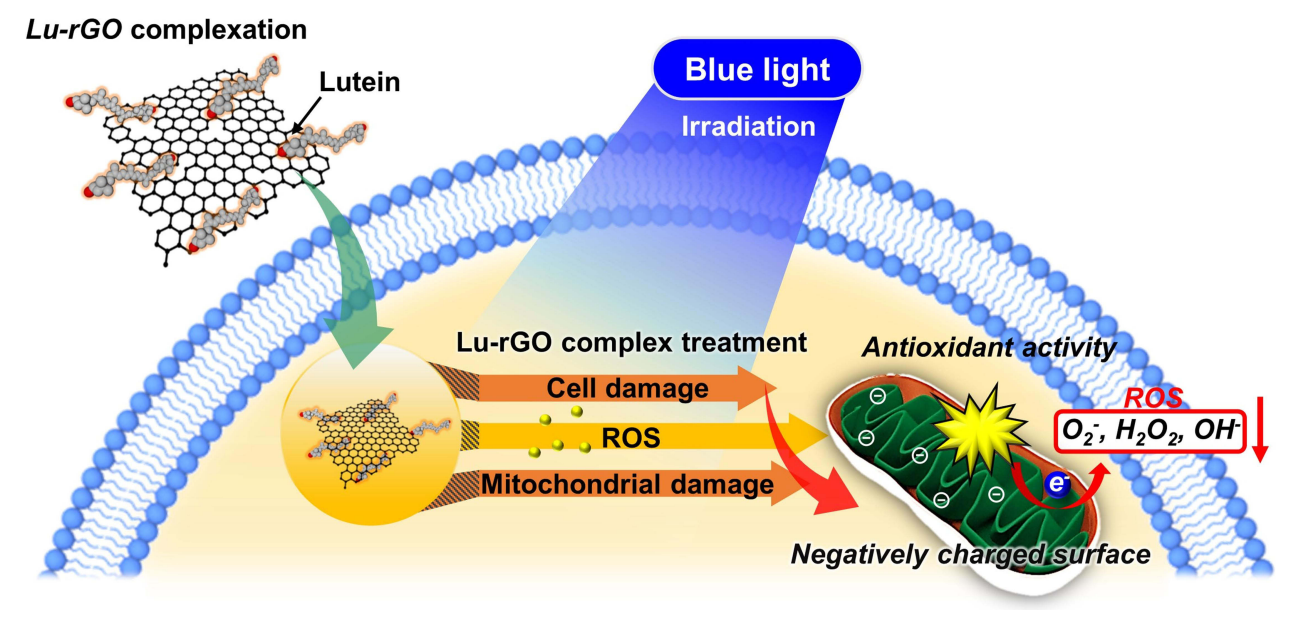

photooxidation and photodestruction and functions as an active high-energy blue light filter. ${ }^{3}$ These beneficial biological functions provide powerful antioxidant and anticancer effects and are induced by a reduction in the absorption of high-energy blue light to protect the macula and skin; these properties are attributed largely to lutein's unique molecular structure of hydroxyl carotenoids and unsaturated double bonds. Therefore, there is close link between the chemical stability, structural configuration, and inherent properties of lutein and its antioxidant and anticancer behaviors. ${ }^{4,5}$ However, lutein must be absorbed by ingestion, as it cannot be synthesized by the human body; furthermore, due to its limited solubility in the aqueous state, its poor absorption and very low bioavailability make it unstable. ${ }^{2}$ From this perspective, appropriate carriers can be used as a feasible route to realizing improved solubility with structural stability. Recently, studies on using nanoscale carriers as a local delivery system for lutein have produced promising results. ${ }^{1,2}$ As the main carotenoid and a key component in various biological processes, lutein is an essential element for human health. Xanthophylls are polar carotenoids containing one or more oxygen atoms; they can be subdivided into hydroxyl carotenoids, which include one or two hydroxyl groups, and keto-carotenoids, which contain ketone groups. ${ }^{6,7}$ Generally, carotenoids react with highly oxidizing species generated in biological systems. Electron transfer, hydrogen extraction, and radical addition occur via one of four distinct routes: single anti-oxygen, hydroxyl radical, hydrogen peroxide, and superoxide. ${ }^{8}$ Additionally, carotenoids have been reported to decrease several reactive oxygen species (ROS). ${ }^{9}$ Therefore, carotenoids present in lutein could be involved in antioxidant activities occurring in the human body.

The main cause of blindness in aging societies is AMD,${ }^{10}$ which is related to stress changes induced in the retinal pigment epithelium (RPE) by various routes. Along with genetics, smoking, poor diet, and age, excessive light exposure is acknowledged to be a risk factor for chronic diseases. ${ }^{11}$ Multiple factors can exacerbate AMD, including exposure to the blue or white light emitted by devices; this is particularly the case in developed countries where accessibility to these devices is widespread. These factors affect the RPE, which protects the retina from the action of free radicals and is involved in the transport of nutrients to photoreceptors. ${ }^{12-16}$ Consequently, oxidative stress occurs in the retina, which is usually closely related to the production of inflammatory cytokines. During early-stage AMD, the accumulation of fluorescent yellow deposits in the macula causes the senescence of RPE cells and increases cellular light sensitivity. Blue light exposure is widely recognized to be a major risk factor for AMD. According to numerous studies, blue light is heavily absorbed by the typical pigment component present in the RPE, resulting in the induction of actinic damage to the retina. ${ }^{6}$ Other recent studies have proposed that the incidence or progression of AMD can be limited by the filtering or blocking of blue light. ${ }^{17-19}$ AMD occurs during 
aging alongside visual deterioration and results from the accumulation of oxidative stress by excessive ROS production, which is understood to be the disease's major pathological factor. ${ }^{12,20-22}$ A significant quantity of oxygen is consumed by the retina, and RPE cells in particular produce substantial ROS. Numerous biological processes within cells are regulated by ROS, including inflammation, apoptosis, and senescence, and it is known that ROS at basal levels are important for cell proliferation. ${ }^{23}$ However, at high concentrations of ROS can be toxic to cells, ${ }^{24}$ and then the promotion of DNA damage and cellular senescence, implicates in the development of a variety of diseases, including cancer and diabetes. Therefore, one of the key considerations for maintaining the homeostasis of the living body and for protecting against oxidative-stress-related cell damage is the preservation of the equilibrium between the production and scavenging of reactive oxygen. An imbalance between the generation and elimination of ROS produces oxidative stress, ${ }^{25,26}$ which results in changes such as apoptosis induction, mitochondrial DNA damage, increases in vascular endothelial growth factors/inflammatory responses, and decreases in antioxidant enzymes. ${ }^{27-30}$ Therefore, ROS are instrumental in damaging biological structures, including cell membranes, DNA, and protein, ${ }^{31}$ and the oxidative stress induced by excessive ROS production causes widespread macromolecular damage. This increases the risk of developing a variety of chronic diseases, including cancer, cardiovascular and neurological diseases, and metabolic syndrome. ${ }^{32}$ Various factors such as smoking, obesity, and aging are responsible for the production of ROS, in particular exposure to blue light (ie, short-wavelength light of $\sim 400-500 \mathrm{~nm}$ ) has emerged recently as an additional contributory factor, and then excessive ROS production of which contributes to retinal RPE damage. ${ }^{33,34}$ All display devices emit blue light, which is a high energy on the visible light spectrum. Extended periodic exposure to blue light can cause gradual oxidative damage to retinal tissues. Not only does blue light exposure produce ROS, but it also causes accumulative oxidative stress to the retina and increases the risk of tissue damage from various ocular disorders. ${ }^{12}$ The generation of free radicals, including ROS, is increased by exposure to blue light, and the breakdown of enzymes involved in the electron transport chain affects mitochondrial functioning, which leads to a deficiency in ATP production and potential cell death. ${ }^{12,35-38}$ The widespread use of various display devices means that exposure to blue light is an ongoing issue, and adjustments are required to mitigate the adverse effects of oxidative stress. Consequently, new ROS-inhibiting materials should be utilized to protect cells and tissues.

Two-dimensional (2D) carbon nanomaterials with unprecedented physical and chemical properties have been developed, including graphene and graphene derivatives. As a result, considerable progress has been made in the spheres of optoelectronics, energy storage devices, biosensing platforms, drug-delivery systems, and tissue engineering applications. ${ }^{39-45}$ Research has focused on using surface modifications to expand the unique properties of these materials by exploiting their large surface areas, considerable chemical functionality, and intrinsic light absorbance. For example, a severely oxidized form of graphene nanosheets (graphene oxide, GO) can be utilized as nanoscale carriers for drug-delivery systems or photosensitizing agents. Different strategies for obtaining eco-friendly and highly biocompatible graphene using green synthesis techniques have been reported. ${ }^{46,47}$ For example, replacing toxic reducing agents with natural plant extracts during GO reduction makes for an ecofriendly, controllable, biocompatible, and cost-effective process. $^{47,48}$

Here, we report a facile and biofriendly route to preparing a novel biomaterial comprising a reduced form of GO (rGO) combined with the powerful oxidant, lutein. The biological effect of the nanoscale lutein-delivery GO sheet material was determined by its direct application and examination under a reduced level of oxidative stress, utilizing a large relative specific surface area with synergistic phytochemical effects. Typically, the blue light emitted by display devices induces dryness or fatigue of the eyes, photoreceptor deformities, and macular degeneration. Therefore, practical research on controlling the risk of oxidative stress, protein denaturation, and retinal cellular aging as a prevention for ocular disease could be beneficial. In the current study, the antioxidant effects and related mechanisms against blue light-induced oxidative stress were investigated to confirm the powerful antioxidant properties of lutein delivered by GO nanocarriers for treating or preventing retinal diseases. An acellular model was used to verify the antioxidant efficacy of the luteinrGO (Lu-rGO) complex by measuring the scavenging ability of free radicals, such as $2.2^{\prime}$-Azino-bis(3-ethylbenzothiazoline-6-sulfonic acid) (ABTS) and 2.2-Diphenyl1-picrylhydrazyl (DPPH), and the inhibition of glutathione (GSH) oxidation. Additionally, ARPE-19 cells, which are 
a human retinal pigment epithelial cell line, were irradiated with blue light from a light-emitting diode (LED) array to generate ROS and induce oxidative stress. The collective dataset and its supporting biological evaluation confirm that ROS were clearly inhibited by treatment with the Lu-rGO complex, cells were protected against damage, and oxidative stress caused by blue light irradiation was reduced.

\section{Materials and Methods}

\section{Synthesis of the Lu-rGO Complex}

GO solutions were synthesized by using expandable graphite (Grade 1721, Asbury Carbon Co. Ltd., USA) according to a modified Hummers method, as described in our previous report. ${ }^{49}$ To reduce GO through lutein, GO at a concentration of $0.1 \mathrm{mg} \mathrm{mL}^{-1}$ was reacted with lutein $(4-\mu \mathrm{M})$ at a temperature of $95^{\circ} \mathrm{C}$. The optimal ratio in the reduction process was adopted from the previous reports. ${ }^{9,50}$ Initially, a stock solution of GO $(1 \mathrm{~mL}$, $\left.\mathrm{C}=1 \mathrm{mg} \mathrm{mL}^{-1}\right)$ was diluted with DI water $(9 \mathrm{~mL})$, and the lutein solution ( $20 \mu \mathrm{L}$ of $2-\mathrm{mM}$ in DI water) was thoroughly mixed. The $\mathrm{pH}$ was maintained within 9-10 by adding $\mathrm{NaOH}(1 \mathrm{~mL}$ of $1-\mathrm{M})$, and then the prepared solution was stirred at $95^{\circ} \mathrm{C}$ at $500 \mathrm{rpm}$. As well known, heat treatment of the GO suspensions under alkaline conditions was highly effective. As the reaction proceeded, the color began to change after $2 \mathrm{~h}$, followed by a reaction for $2 \mathrm{~h}$ more (final concentration of GO: $0.1 \mathrm{mg} \mathrm{mL} \mathrm{m}^{-1}$, lutein: 4- $\mu \mathrm{M})$. Heating the GO suspensions under alkaline conditions was an effective method for a graphene solution. UV-Vis spectra in the wavelength range of $200-800$ $\mathrm{nm}$ was measured by an ultraviolet-visible (UV-Vis) spectrophotometer (Ultrospec 6300 Pro, GE Healthcare Life Sciences, Buckinghamshire, U.K.), and the zeta potential and size were determined by dynamic light scattering (DLS) using data transfer assistance software and a Zetasizer Nano ZS90 instrument (Malvern Instruments, Malvern, U.K.).

\section{Material Characterization}

Fourier-transform infrared spectroscopy (FT-IR) analyses were performed to confirm the presence of diverse functional groups and the formation of rGO. The FT-IR spectra of lutein, GO, and the Lu-rGO complex were measured in the range of $4000-400 \mathrm{~cm}^{-1}$ using the attenuated total reflectance (ATR) recorded by an FT-IR spectrophotometer (Spectrum GX, PerkinElmer Inc., Boston, M.A.,
U.S.A.). The area under the peaks was used to calculate the reduction efficiency with the following formula:

Reduction efficiency $(\%)=(\mathrm{GO}-\mathrm{rGO}) / \mathrm{GO} \times 100$.

Raman spectra for GO, lutein, and Lu-rGO complex were measured by Raman spectroscopy (UniNanoTech, UniRam-II) with $532 \mathrm{~nm}$ laser excitation in the 1300$3000 \mathrm{~nm}$ wavelengths, and the exciting laser beam was focused on the samples using a microscopic objective lens. The chemical states of the elements comprising GO and the Lu-rGO complex were examined by X-ray photoelectron spectroscopy (XPS, Axis Supra, Kratos). The XPS spectra were calibrated to the C1s peak for graphitic carbon located at $284.8 \mathrm{eV}$, and Shirley-type background and were analyzed using the CasaXPS software. To observe the samples with highly magnified features, a small droplet of the dispersed GO and Lu-rGO solution was placed onto a carbon-coated copper grid and sufficiently dried at room temperature. The surface morphologies of the GO and the Lu-rGO complex were characterized by transmission electron microscopy (TEM, TALOS F200X operated at $200 \mathrm{kV})$.

\section{Antioxidant Assays}

Both ABTS and DPPH are relatively stable radicals and are widely used for determining the antioxidant activity of substances. ${ }^{51,52}$ First, an ABTS assay was performed to indirectly confirm the radical scavenging ability in the human body. The ABTS radical was activated by mixing 7.4-mM ABTS and 2.6-mM potassium persulfate before reacting the mixture in the dark at room temperature for 18-24 h. Then, the activated $\mathrm{ABTS}^{+}$radical was diluted with phosphate-buffered saline (100-mM at $\mathrm{pH} 7.4)$ to obtain a solution with an absorbance of approximately 1.4 at $734 \mathrm{~nm}$. Essentially, $\mathrm{ABTS}^{+}$radicals are dark blue-green in color, which lightens when reacted with antioxidants. The GO and the $\mathrm{Lu}-\mathrm{rGO}$ complex were added to $1 \mathrm{~mL} \mathrm{ABTS}^{+}$radical solution at a concentration of 1 and $2 \mu \mathrm{g} \mathrm{mL}^{-1}$ and were reacted at room temperature for $30 \mathrm{~min}$. Arbutin was used as a positive control, and absorbance was determined at $734 \mathrm{~nm}$ using a UV-Vis spectrophotometer. The scavenging ability of the ABTS radical was calculated using the following equation:

Scavenging ability $(\%)=($ control - sample $) /($ control $) \times 100$

The antioxidant activity was also measured by assessing the DPPH radical scavenging activity. This is commonly used to determine antioxidant efficacy and was measured in this study via an assay. The DPPH radical 
was freshly prepared by dissolution in equal volumes of methanol and distilled water (DPPH: $0.008 \mathrm{mg} \mathrm{mL}^{-1}$, $\mathrm{MeOH}: \mathrm{DW}=1: 1)$. The Lu-rGO complex $(10,20$ $\mu \mathrm{g} \mathrm{mL}^{-1}$ ) was added to $1 \mathrm{~mL}$ of the prepared $\mathrm{DPPH}$ radical solution. Then, it was reacted in the dark at room temperature, and the absorbance at $540 \mathrm{~nm}$ was determined using a microplate reader (Wallac 1420, PerkinElmer, Boston, M.A., U.S.A.). Arbutin was used as a positive control. The scavenging ability of the DPPH radical was calculated using the following equation:

Scavenging ability $(\%)=($ control - sample $) /($ control $) \times 100$

Oxidative stress affects the balance of cellular thiol, and GSH exists in both the reduced sulfhydryl form (GSH) and the GSH disulfide (GSSG) oxidized forms, which can be decreased in ratio by oxidative stress (GSH/GSSG), ie, the concentration of intracellular GSH is a key indicator of oxidative stress. An assay of GSH oxidation by the $\mathrm{Lu}-$ rGO complex was performed under acellular conditions using a procedure adapted from previous publications. ${ }^{52-55}$ 0.4-mM reduced GSH was dissolved in 50-M bicarbonate buffer ( $\mathrm{pH}$ 8.6) before being exposed to GO, the $\mathrm{Lu}-\mathrm{rGO}$ complex, and 1- $\mathrm{M} \mathrm{H}_{2} \mathrm{O}_{2}$. The mixture was stirred continually for $4 \mathrm{~h}$ at a rate of $200 \mathrm{rpm}$ under a blocking light at room temperature. Then, $0.4 \mathrm{~mL}$ of Tris-HCl buffer $(\mathrm{pH}$ 8.3) was added to $0.7 \mathrm{~mL}$ of the reaction mixture, and the quantity of non-oxidized GSH was quantified using a spectrophotometer and Ellman's reagent (5,50-dithiobis [2-nitrobenzoic acid] [DTNB]). After the addition $10 \mu \mathrm{L}$ of $100-\mathrm{mM}$ DTNB, the remaining thiol in the reaction medium was quantified, and the absorbance was measured at $412 \mathrm{~nm}$ by a microplate reader. The loss of GSH was calculated using the following equation:

Loss of $\operatorname{GSH}(\%)=(1-$ sample $) /($ control $) \times 100$

\section{Cell Culture and Cell Viability}

The human RPE cell line ARPE-19 (ATCC ${ }^{\circledR}$ CRL 2302 ${ }^{\text {TM }}$ ) was cultured in an incubator using DMEM/F-12 medium containing $10 \%$ heat-inactivated fetal bovine serum and $1 \%$ penicillin-streptomycin at a temperature of $37^{\circ} \mathrm{C}$ with $5 \% \mathrm{CO}_{2}$. For the experiments, the cells were passaged two to three times weekly. Cells were seeded in 24-well plates $\left(3 \times 10^{4}\right.$ cells/well $)$. After $24 \mathrm{~h}$, the cells were treated with the Lu-rGO complex $\left(1,2\right.$, and $\left.4 \mu \mathrm{g} \mathrm{mL}^{-1}\right)$ and were incubated for $48 \mathrm{~h}$. Cell viability was measured using a reagent (WST-1) (Ez-Cytox; iTSBiO, Seoul, South Korea) to measure mitochondrial dehydrogenases in viable cells as a colorimetric assay for cell quantification. Then, $10 \%$ of the reagent was added to each well as described previously, ${ }^{27}$ and absorbance was determined at $450 \mathrm{~nm}$ using a microplate reader.

\section{Oxidative Stress Induction by Blue Light and Intracellular ROS Analysis}

Cellular oxidative stress was induced by blue light stimulation. The ARPE-19 cells were seeded in 6-well plates ( 2 $\times 10^{5}$ cells/well $)$. The blue light-irradiated cells $(\sim 450$ $\mathrm{nm}$ ) were incubated for $2 \mathrm{~h}$ at $37^{\circ} \mathrm{C}$ with $5 \% \mathrm{CO}_{2}$. The process was repeated three times. ROS measurements were obtaining using a CM- $\mathrm{H}_{2}$ DCFDA molecular probe (Invitrogen, C.A., U.S.A.), which is an intracellular ROS probe and free radical sensor; it is a typical oxidative stress indicator and is one of the most popular systems for directly evaluating cellular redox states. ${ }^{24,56}$ The analysis was conducted in accordance with the manual of the ROS probe. Before the cells were exposed to blue light, the $\mathrm{Lu}-$ rGO complex was sonicated for $1 \mathrm{~h}$ and pre-treated on cells for $1 \mathrm{~h}$, then treated cells were exposed to blue light for $2 \mathrm{~h}$ a day for 3 days. Subsequently, the cells were collected with trypsin-EDTA. Then, DCFDA $(5-\mu \mathrm{M})$, which is a commonly used intracellular free radical (ROS) marker, was added. The light was blocked, and the cells were reacted at $37^{\circ} \mathrm{C}$ for $30 \mathrm{~min}$. DCFDA entered the cells. When ROS is present, it is oxidized and cleaved with DCF to produce a green fluorescence. Intracellular fluorescence values were measured at $485 / 535 \mathrm{~nm}$ by a microplate reader. ARPE-19 cells pre-treated with $0.1 \mathrm{mg} \mathrm{mL}^{-1}$ of the Lu-rGO complex for $1 \mathrm{~h}$ were irradiated with blue light for $4 \mathrm{~h}$ at $37^{\circ} \mathrm{C}$. They were incubated for $24 \mathrm{~h}$, and the process was repeated. Then, the cells were treated with DCFDA at $37^{\circ} \mathrm{C}$ for 30 min under dark conditions. Fluorescence micrographs were captured using a confocal laser scanning microscope, and the degree of fluorescence was quantified using ImageJ software (Cell Signaling Technology, Beverly, M.A., U.S.A.). The lysosome content of the cells was analyzed using a $50-\mathrm{nM}$ LysoTracker Green DND-26 (Cell Signaling Technology, Beverly, MA, USA). The dye was reacted with the cells in the dark, and the fluorescence intensity was analyzed at an excitation wavelength of $488 \mathrm{~nm}$ and an emission wavelength of $525 \mathrm{~nm}$ using flow cytometry. A data analysis was conducted using CXP software 2.0 (Beckman Coulter, Inc., Brea, C.A., U.S.A.). 


\section{Results and Discussion}

\section{The Synthetic Route to the Lu-rGO}

\section{Complex and the Antioxidant Process}

Figure 1 illustrates a scheme of our approach for the complexation of lutein and GO and the mechanism of the antioxidant process when exposed to blue light irradiation. First, the complexation of the lutein and GO involved an amenable chemical reaction between the hydroxyl end groups of lutein and the abundant oxygen functional groups of GO sheets in an aqueous solution. When the dominant intramolecular interactions were controlled with an optimized ratio of two molecules, the major portion of the oxygen functional groups on the surface of the GO was separated by the lutein, transforming the GO to a reduced form (ie, rGO) (Figure 1A). RPE cells are pigmented cells that exist outside the retinal sensory nerve. ${ }^{57}$ They form a monolayer on the outermost side of the retina and are associated with retinal development, light absorption, epithelial transport, the visual cycle, phagocytosis, hormone secretion, and immunity regulation. The macula is an area of the eye in which many photoreceptor cells responsible for visual acuity are concentrated. It is affected by AMD, and its function deteriorates with aging, leading to a loss of vision or blindness. ${ }^{58}$ Recently, the blue light emitted by devices has been found to cause oxidative cell stress in the macula and retina (Figure 1B). Accordingly, this study attempted to investigate the antioxidant effects of the Lu-rGO complex by subjecting RPE cells to blue light irradiation from organic LEDs (OLEDs). The main objective was to investigate possible routes within the antioxidant system for the interaction between the lutein complex, stable rGO nanocarriers, and RPE cells. The LurGO complex was prepared in the form of an aqueous solution and was applied to the ARPE-19 cells to assess their bioavailability. Since one of the main benefits of the antioxidant complex is its inhibition of free radicals, it was anticipated that it would demonstrate some excellent antioxidant effects in response to the redox regulation of blue light-induced ROS. This hypothesis was based on the fact that the Lu-rGO complex reduces the intracellular increase in ROS production resulting from blue light exposure, and the consequent decrease in ROS levels inhibits
A

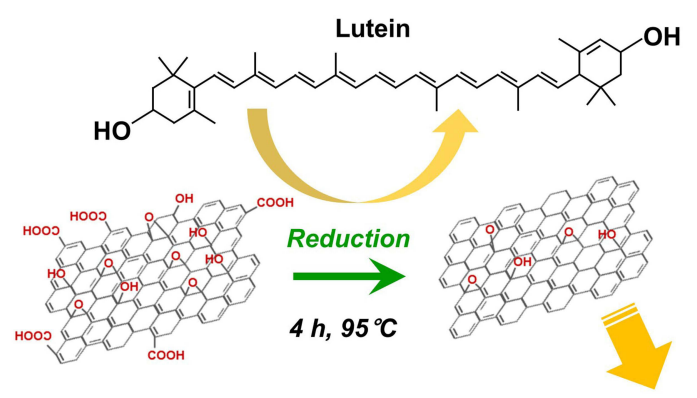

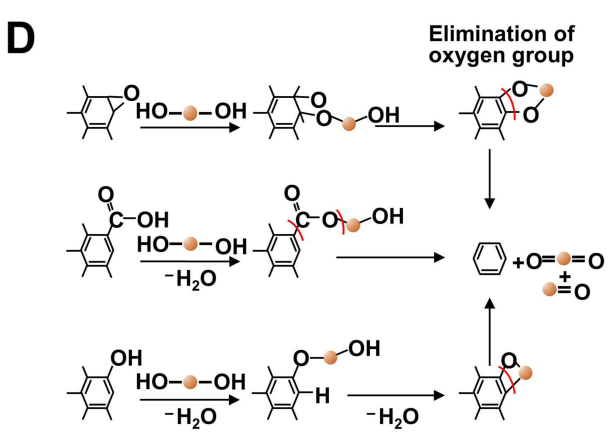

B

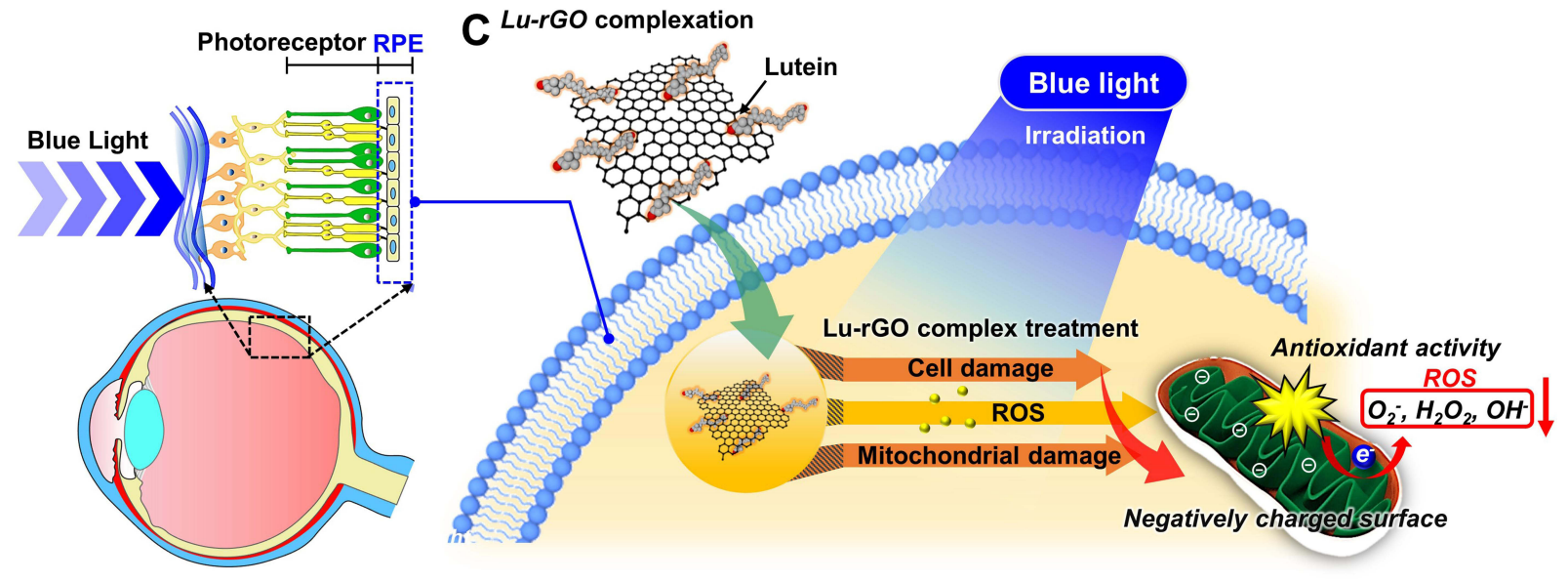

Figure I The proposed scheme for the complexation of lutein and graphene oxide (GO) and the related mechanisms of the antioxidant process under exposure to blue light irradiation. (A) The reduction of GO caused by a separation of the oxygen functional groups from the surface functioned with lutein, transforming GO to the reduced form of rGO complexed the Lu-rGO. (B) A conceptual schematic of the macula/RPE cells under oxidative stress induced by incident blue light. (C) Cell protecting capability of the Lu-rGO complex via suppression of the generation of oxidative stress and reduction of the superoxide anion, hydrogen peroxide, and hydroxyl radicals as antioxidant pathways under blue light irradiation. (D) Possible surface interactions at biologically active interfaces binding with functional groups of biomolecules. 
oxidative stress, cellular senescence, and associated damage. From this perspective, it was expected that the antioxidant pathways of the Lu-rGO complex in ARPE-19 cells would decrease the superoxide anion, hydrogen peroxide, and hydroxyl radicals, thereby protecting the cells by suppressing the production of oxidative stress (see Figure 1C). This could be attributed not only to the antioxidant ability of lutein, but also to the unique 2D geometry and chemical structure of GO. Due to their specific physical and chemical properties, various surface functional groups create surfaces with biologically active interfaces that can bind easily to biomolecules (Figure 1D). Therefore, nanoscale planar sheets or encapsulation shells of graphene-based nanomaterials could cross physical barriers to chemical antioxidant transport and achieve a higher level of antioxidant efficacy. Accordingly, based on the outcomes of the reliable evaluation process, we propose the Lu-rGO complex as an important stable nanocarrier in the antioxidant system.

\section{Characterization of GO and the Lu-rGO Complex}

A full characterization was performed on the prepared the Lu-rGO complex before it was used in the bioavailability tests. Graphs showing the appearance of typical ultravioletvisible (UV-Vis) spectra in the $200-800 \mathrm{~nm}$ range are provided in Figure 2A, in which a clear change in the position of the absorption peak between 370 and $380 \mathrm{~nm}$ to a slightly broader trend can be observed. Additionally, as the GO reduction process progressed, the solution was observed by the naked eye to change color from the yellowishbrown of the GO to the dark black of the $\mathrm{Lu}-\mathrm{rGO}$ complex (see Figure 2B). The dynamic light scattering (DLS) technique was used to determine the size distributions and zeta

B
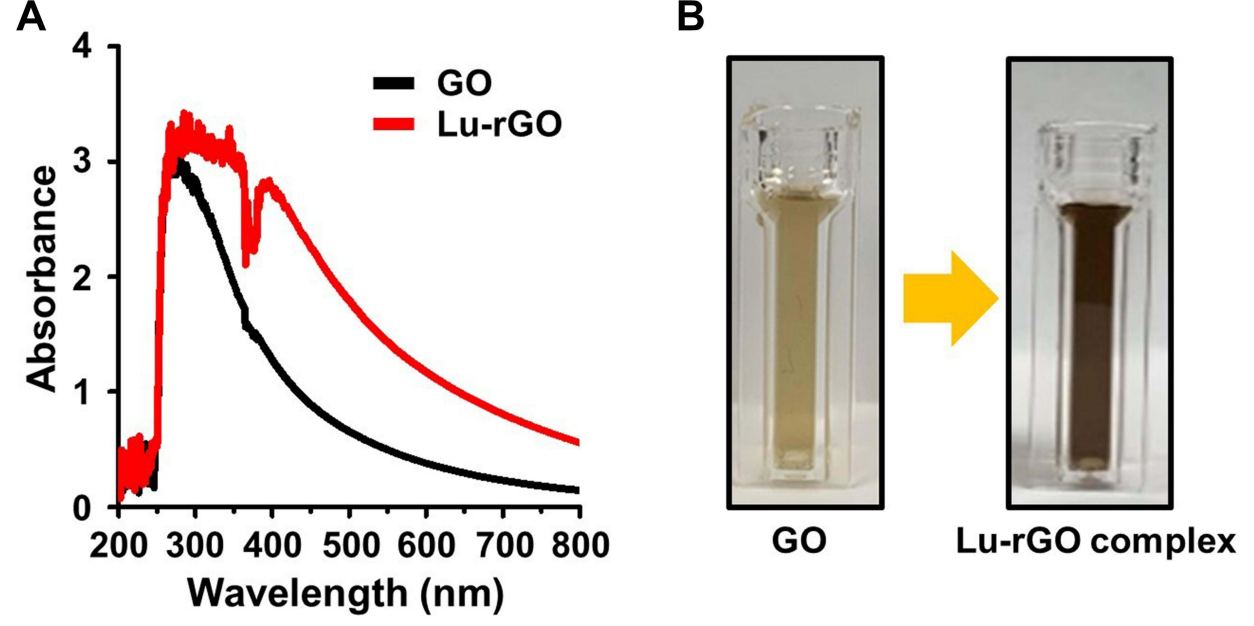

C

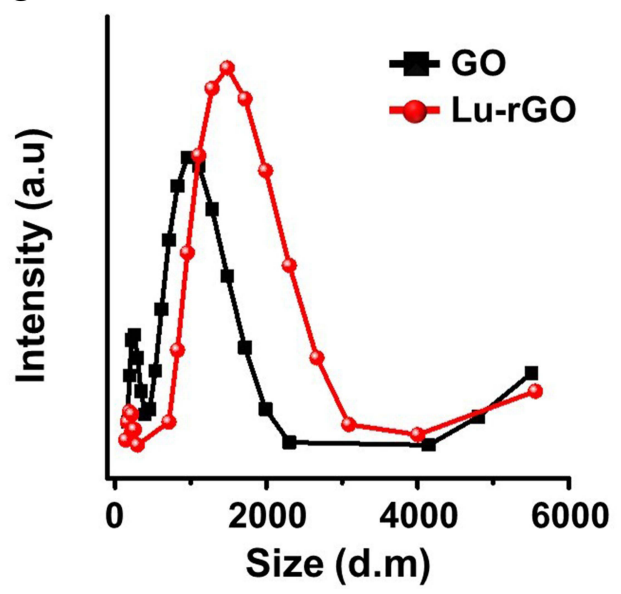

D

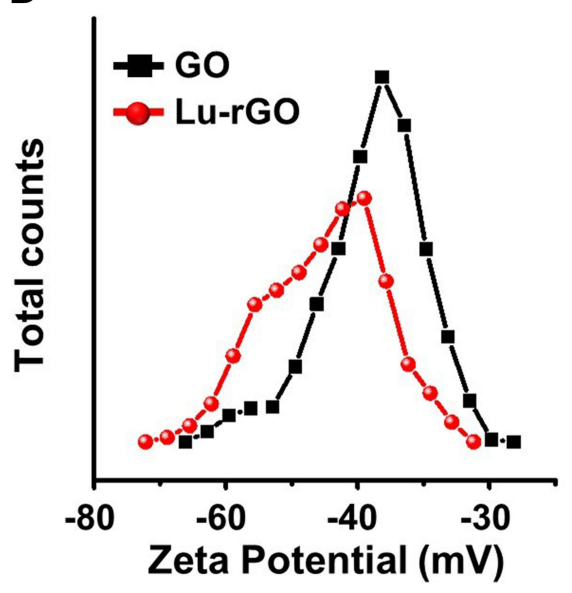

Figure 2 (A) UV-Vis spectra of GO and the Lu-rGO complex, and (B) color change representing the reduction through the reaction of GO (0.I $\mathrm{mg} \mathrm{mL}^{-1}$ ) and lutein (4$\mu \mathrm{M})$ at $95^{\circ} \mathrm{C}$ and $500 \mathrm{rpm}$ for $4 \mathrm{~h}$. (C and D) Size and zeta potential distribution of GO and the Lu-rGO complex as measured by DLS.

Abbreviation: DLS, dynamic light scattering. 
potential for each $\mathrm{GO}$ and $\mathrm{Lu}-\mathrm{rGO}$ complex sample. The results show that the attachment of lutein molecules slightly increased the size distribution of the Lu-rGO complex compared with the original GO within a peak intensity from $\sim 762$ and $\sim 1334 \mathrm{~nm}$ for the GO and the $\mathrm{Lu}-\mathrm{rGO}$ complex, respectively (Figure 2C). According to the zeta potential distribution measurements, the individual main peaks represent fairly well-dispersed colloidal stabilities for the prepared samples. Moreover, a relatively broader deviation that contributed to increased signal scattering was observed with the Lu-rGO complex in which the mean values were centered at -38.6 and $-45.2 \mathrm{mV}$ for the $\mathrm{GO}$ and the Lu-rGO complex, respectively (Figure 2D). As a result, and largely thanks to a favorable interaction between participating colloids, the successful design and stabilization of the lutein-molecule-laden rGO complex without agglomeration or sedimentation was confirmed.

As a starting material, GO comprises multiple surface functional groups, including carboxyl, hydroxyl, and epoxy groups. ${ }^{59}$ The presence of surface oxygenated functional groups corresponding to carboxyl, hydroxyl, and epoxy molecules was confirmed via Fourier transform infra-red (FT-IR) spectroscopy, which also monitored the change in corresponding peak intensities following $\mathrm{GO}$ reduction (Figure 3). Since rGO includes multiple surface oxygenated functional groups in addition to other functional groups, including hydroxyl $(\mathrm{C}-\mathrm{OH})$, carboxyl $(\mathrm{COOH})$, epoxy $(\mathrm{COC})$, and carbonyl $(\mathrm{C}=\mathrm{O})$ groups, information on newly engaged functional groups and chemical conformational changes could be extracted from the spectral measurements. This process occurred on the surface of the GO during the complementary interactions with the lutein molecules. The FT-IR spectra of GO, the $\mathrm{Lu}-$ rGO complex, and the separated lutein are presented in Figure 3A. Several main peaks can be observed centered at $3349.48,3343.71$, and $2115.69 \mathrm{~cm}^{-1}$, resulting from $\mathrm{O}-\mathrm{H}$, $\mathrm{N}-\mathrm{H}$, and $\mathrm{C} \equiv \mathrm{C}$ stretching, respectively. A peak appeared at $1640 \mathrm{~cm}^{-1}$ due to either $\mathrm{C}=\mathrm{C}$ stretching or to the $\mathrm{N}-\mathrm{H}$ bending, which represents a carbon-carbon double bond. As shown in the enlargement in Figure 3B, the Lu-rGO complex exhibited a slightly different peak at $1045 \mathrm{~nm}$. Based on the FT-IR measurement, the reduction efficiency defined by area was found to be $87.3 \%$, as described in Table 1.

To obtain additional information, the structural properties of the GO and the $\mathrm{Lu}-\mathrm{rGO}$ complex were investigated using Raman spectroscopy, as shown in Figure 4A. The Raman spectra of both the original GO (green) and the Lu-rGO complex (red and blue) exhibited two bands mainly at 1376 and $1619 \mathrm{~cm}^{-1}$ for the $D$ and $G$ bands, respectively. The $\mathrm{G}$ band is known to be associated with the $\mathrm{sp}^{2}$ carbon double-bond vibration of the carbon-based hexagonal structure, and the $\mathrm{D}$ band indicates that the vibration of the $\mathrm{sp}^{3}$ carbon dangling bond was affected by structural defects, including the vacancy of carbon atoms. $^{60-62}$ Of note was the detection of two different Raman peaks (depending on the measurement location) for the solid film from the $\mathrm{Lu}-\mathrm{rGO}$ solution. For example, the familiar coffee-ring effect was observed during the colloidal droplet deposition process on the flat substrate

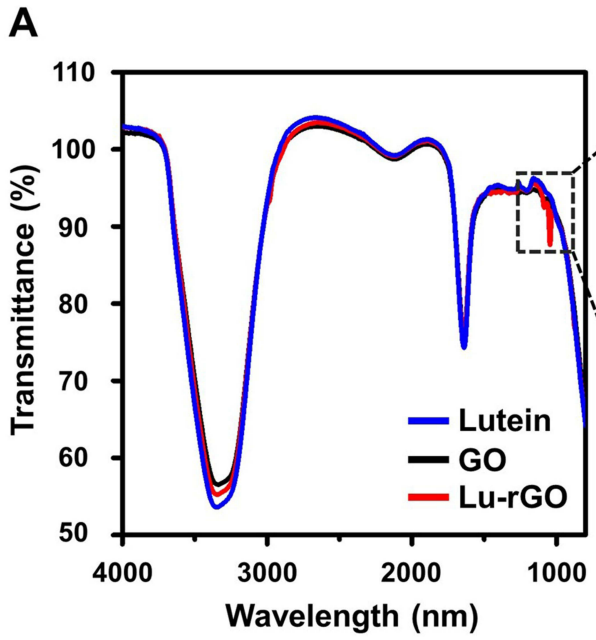

B

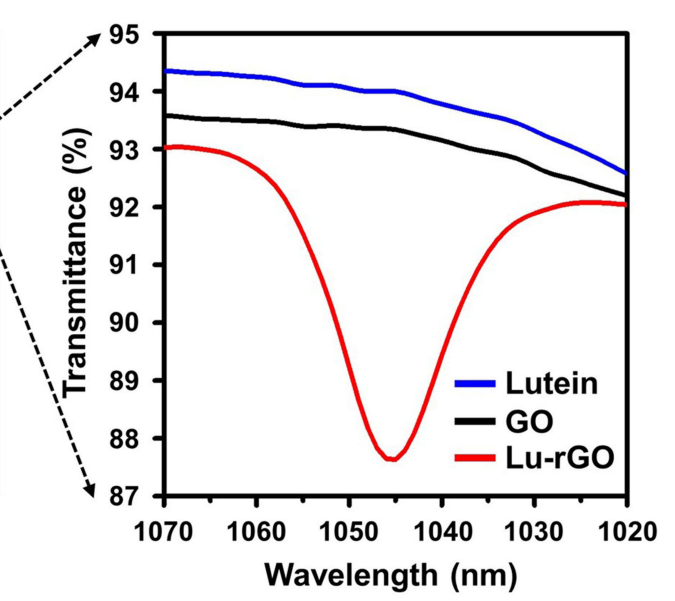

Figure 3 FT-IR spectra of GO and the Lu-rGO complex. (A) The peaks for lutein (blue line), GO (black line), and the Lu-rGO complex (red line) recorded by an FT-IR spectrophotometer using the ATR method in the range of $4000-400 \mathrm{~cm}^{-1}$. (B) The enlarged peak of the Lu-rGO complex at I045 $\mathrm{nm}$.

Abbreviation: FT-IR, Fourier-transform infrared spectroscopy. 
Table I The Reduction Efficiency of GO Using Lutein by FT-IR Spectral Analysis

\begin{tabular}{|c|c|c|c|c|}
\hline Samples & Area & $\begin{array}{l}\text { GO- } \\
\text { rGO }\end{array}$ & $\begin{array}{c}\text { (GO- } \\
\text { rGO)/GO }\end{array}$ & $\begin{array}{c}\text { Reduction } \\
\text { Efficiency (\%) }\end{array}$ \\
\hline GO & 70.193 & 0 & 0 & 0 \\
\hline Lu-rGO & 8.921 & 62.272 & 0.873 & 87.3 \\
\hline
\end{tabular}

$\left(\mathrm{Si} / \mathrm{SiO}_{2}\right)$, and the subsequent spontaneous sorting process was evident at the edge of the receding meniscus. ${ }^{49,63}$ When observed from the outermost to the innermost regions, the intensity of the thicker peripheral ring is greater than in the central region of the $\mathrm{Lu}-\mathrm{rGO}$ film; this indicates that the major portion of the Lu-rGO complex was mixed with the pure rGO separately, forming complemental dispersions in the solution. An evaluation of the intensity ratio $\left(\mathrm{I}_{\mathrm{D}} / \mathrm{I}_{\mathrm{G}}\right)$ to characterize the sequence or disorder degree of carbon materials corroborated this observation. The $\mathrm{I}_{\mathrm{D}} / \mathrm{I}_{\mathrm{G}}$ ratio of 0.98 demonstrated by the $\mathrm{Lu}-\mathrm{rGO}$ complex was slightly higher than that of the original $\mathrm{GO}$ at 0.89 . The higher ratio of the $\mathrm{Lu}-\mathrm{rGO}$ complex could be attributed to the recovery of the $\mathrm{sp}^{2}$ network and the formation of unrepaired defects following the removal of multiple oxygen functionalities. These findings indicate that the surface of the GO underwent transformation by lutein to remove the oxygen groups as effective reducing agents, while the unreacted rGO with lutein formed a partially mixed phase with the Lu-rGO complex in the prepared solution.

As shown in Figure 4B and $C$, the fraction of the functional groups and the changes of the surface state from $\mathrm{GO}$ to the $\mathrm{Lu}-\mathrm{rGO}$ complex were analyzed using $\mathrm{X}$-ray photoelectron spectroscopy (XPS); the summarized XPS spectra can be found in Figure S1. The XPS spectra $\left(\mathrm{C}_{1 \mathrm{~s}}\right)$ of $\mathrm{GO}$ the exhibit three principal peaks corresponding to $\mathrm{C}-\mathrm{C} \mathrm{sp}{ }^{2}(\sim 284.8 \mathrm{eV}), \mathrm{C}-\mathrm{O}-\mathrm{C}(\sim 286.6 \mathrm{eV})$, and $\mathrm{O}-$ $\mathrm{C}=\mathrm{O}(\sim 288.2 \mathrm{eV})$ components, as presented in Figure 4B. Conversely, in the case of Lu-rGO complex at $289.7 \mathrm{eV}$, an additional peak was observed corresponding to the $\mathrm{HO}$ $\mathrm{C}=\mathrm{O}$ bond (Figure $4 \mathrm{C}$ ). Despite the dominance of the $\mathrm{C}-\mathrm{C}$ $\mathrm{sp}^{2}$ peak in $\mathrm{GO}$ and in the Lu-rGO complex, a significant decrease in the peak intensities of the oxygen functional groups (ie, $\mathrm{C}-\mathrm{O}-\mathrm{C}, \mathrm{O}-\mathrm{C}=\mathrm{O}$, and $\mathrm{HO}-\mathrm{C}=\mathrm{O}$ ) of the $\mathrm{Lu}-$ rGO complex was observed compared with the GO. This indicates that in the Lu-rGO complex, there was an increase in the relative percentage of $\mathrm{sp}^{2}$ carbon $(\mathrm{C}-\mathrm{C})$ bonds and a decrease in the carbon-oxygen $(\mathrm{C}-\mathrm{O})$ bonds, which suggests there was a strong reaction between the GO reduction and the lutein. Therefore, it was confirmed that our proposed biofriendly, facile, and naturally induced process resulted in a high-quality of the Lu-rGO complex without the need for any toxic reducing agents. Transmission electron microscopy (TEM) was also used to investigate the nanoscopic morphological details of GO and the Lu-rGO complex, as presented in Figure 4D. The representative images of the film structure on the TEM grid reveal interesting morphological evolutions by GO surface reactions with lutein. The original GO exhibits numerous nanoscale folds and wrinkles, which are formed in a stacked and layered structure. Conversely, in the TEM image for the Lu-rGO complex, fewer folds and wrinkles over the lutein-covered surface area are evident due to tight molecular binding; however, as denoted by the yellow arrows, a sparsely aggregated form within the structure was detected (Figure 4D). This series of experiments confirmed the successful transformation of the GO sheets into the Lu-rGO complex by the removal of oxygen groups from the edges and basal planes of the GO without the use of any toxic chemicals or other reducing agents.

\section{Antioxidant Activities of GO and the Lu- rGO Complex with the Acellular Model}

The direct reaction rates of antioxidant molecules with free radicals of stable use in acellular assays are an indicator of antioxidant activity. This study used ABTS and DPPH, which are widely used free radicals, as reliable and typical probes for evaluating the antioxidant activity at the molecular level. ${ }^{64}$ First, an ABTS assay, which measures specific color changes by reacting with the free radicals in antioxidants, was used to determine the effects of scavenging free radicals. When the Lu-rGO complex was added to the aqueous ABTS radical solution, the elimination of the radicals caused the color to fade (Figure 5A). The absorbance at $734 \mathrm{~nm}$ was determined; this revealed high levels of radical scavenging activity in the Lu-rGO complex compared with the control group and an increase in concentration dependence (Figures 5B and $\mathrm{S} 2$ ). The concentrations of the GO and the $\mathrm{Lu}-\mathrm{rGO}$ complex were $16.98 \%$ and $52.64 \%$ at $1 \mu \mathrm{g} \mathrm{mL} \mathrm{m}^{-1}$, respectively, and $77.22 \%$ and $91.69 \%$ at $2 \mu \mathrm{g} \mathrm{mL}^{-1}$, respectively. In particular, there was a higher increase in the ABTS radical scavenging activity of the Lu-rGO complex (91.69\%) compared with the lutein (1.49\%) and the GO alone 
A

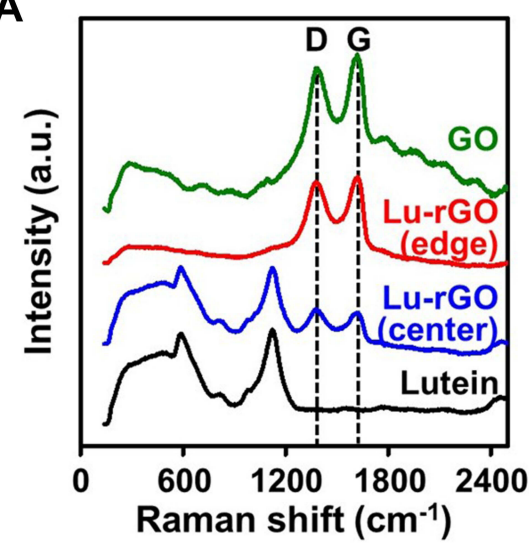

B

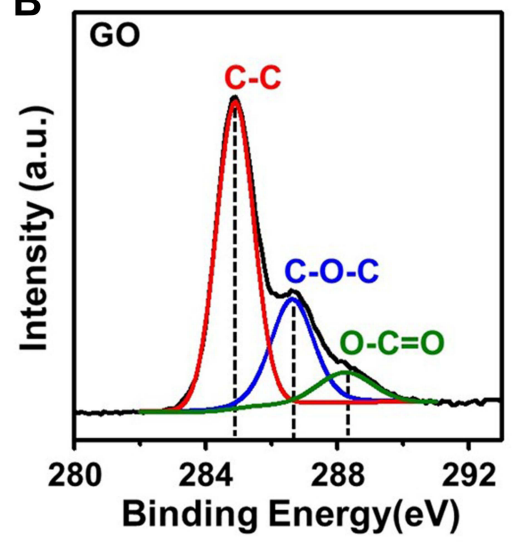

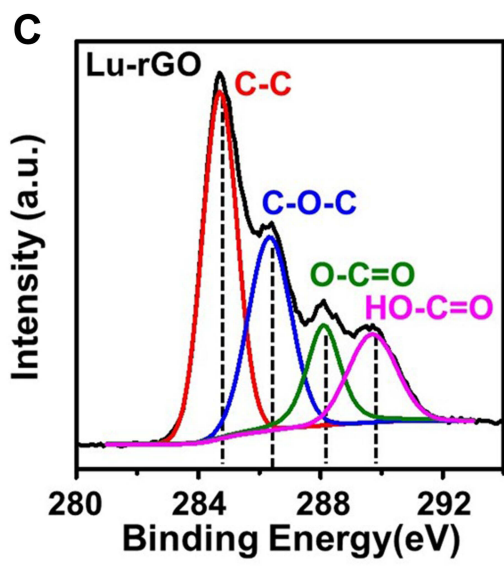

D
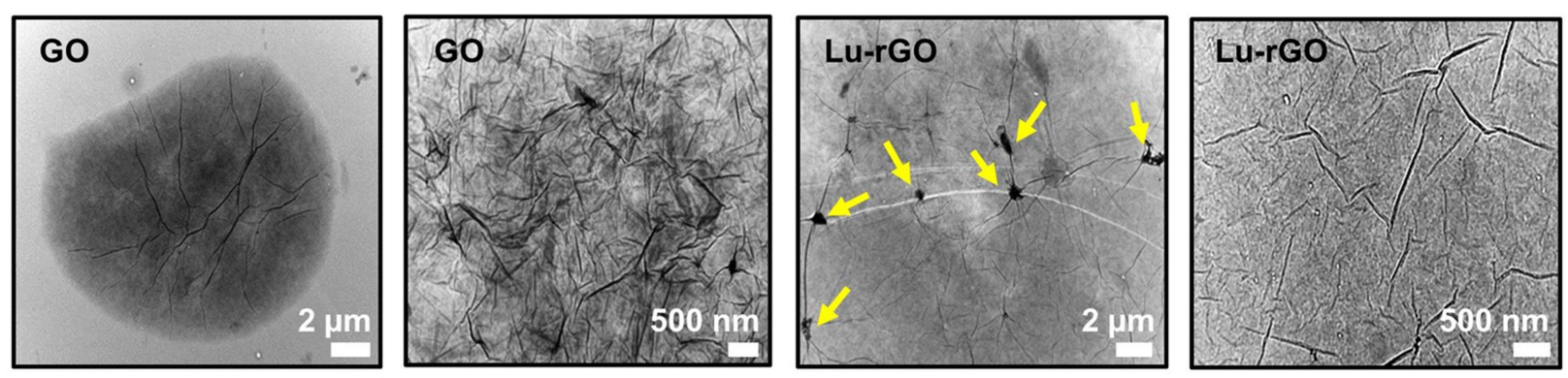

Figure 4 (A) Raman spectra of lutein, GO, and the Lu-rGO complex. (B and C) Chemical component survey by XPS spectra ( $\mathrm{C}_{\mathrm{Is}}$ ) for the analysis of the functional group fractions and the changes of the surface state from GO to the Lu-rGO complex. (D) Highly magnified morphological features of GO and the Lu-rGO complex measured by TEM; the yellow arrows indicate spontaneously formed nanowrinkled nanostructures over the lutein-covered rGO surface.

Abbreviations: XPS, X-ray photoelectron spectroscopy; TEM, transmission electron microscopy.

(77.22\%) at the same concentrations, which confirmed the antioxidant effect of the Lu-rGO complex (Figure S3).

Next, the antioxidant activity resulting from the reduction process was assessed using the nitrogen-centered DPPH radical. Because the antioxidants can donate hydrogen to free radicals to form non-radical species, ${ }^{65,66}$ the antioxidant effect of the Lu-rGO complex could be estimated by measuring color changes upon the application of the free radical-containing reagent (DPPH). Figure 5C reveals that in the direct comparison of concentrationdependent criteria between the control group without the GO and the Lu-rGO complex, the DPPH radical scavenging ability expressed by the Lu-rGO complex was higher $\left(10 \mu \mathrm{g} \mathrm{mL}^{-1} / 17.5 \%\right.$ and $\left.20 \mu \mathrm{g} \mathrm{mL}^{-1} / 26.94 \%\right)$ than the GO alone $\left(10 \mu \mathrm{g} \mathrm{mL} L^{-1} / 14.66 \%\right.$ and $\left.20 \mu \mathrm{g} \mathrm{mL}^{-1} / 23.53 \%\right)$. Specifically, the Lu-rGO complex inhibited around $30 \%$ of the free radicals at the treated concentration regime. More importantly, the DPPH scavenging activity of the Lu-rGO treatment was demonstrated to be higher (26.94\%) than the lutein (13.27\%) and the GO (23.53\%) alone, confirming the synergistic antioxidant effect of the complexation (Figure S4). As analyzed, the easy transfer of electrons or hydrogen atoms and their transformation into stable diamagnetic molecules enabled the $\mathrm{Lu}-\mathrm{rGO}$ complex to neutralize the free DPPH radicals. The enhanced ABTS and DPPH scavenging activity that originated from the $\mathrm{Lu}-\mathrm{rGO}$ complex could be attributed to the antioxidant capabilities of lutein and the reduced contact between GO and lutein, where an enhanced antioxidant activity developed with the assistance of the nanoscale carriers. Additionally, we contribute the results to the higher solubility in the aqueous phase of the Lu-rGO complex and the antioxidant capacity of lutein in nanocarriers. Despite GO becoming less effective as a hydrogen donor due to its relatively weak activity, the GO and the Lu-rGO complex can donate electrons or hydrogen atoms and react with free radicals in a dose-dependent manner with different degrees of binding. Due to the responses of DPPH and ABTS during the hydrogen donation process, the observed trend indicates that the enhancement of the antioxidant activity of the Lu-rGO complex is attributed largely to the combinatorial synergistic effect on the delicate interactions between lutein and GO. ${ }^{65-72}$ 
A
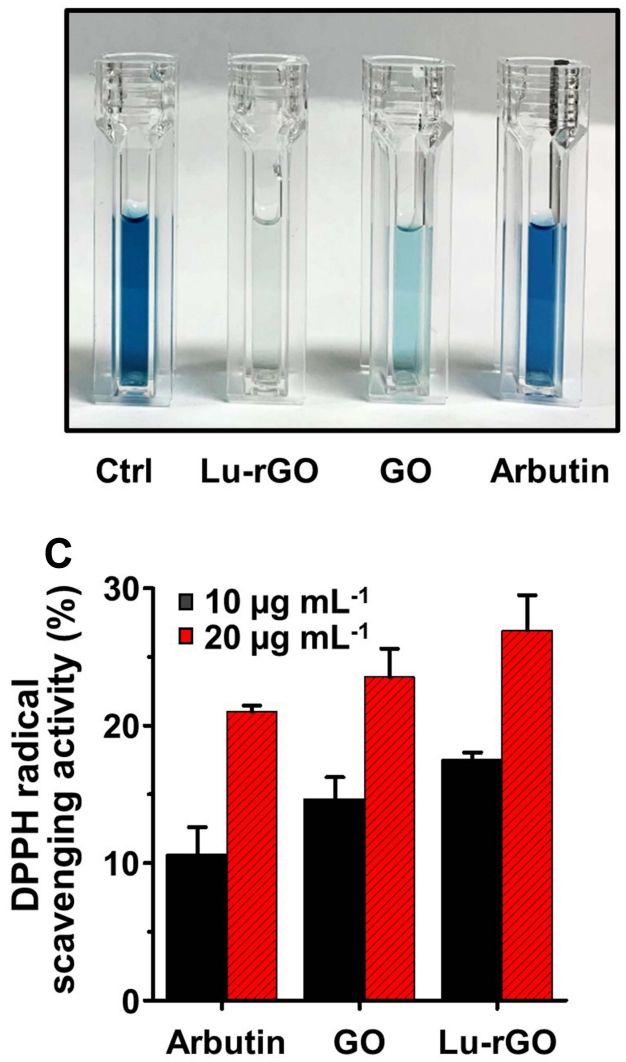

B

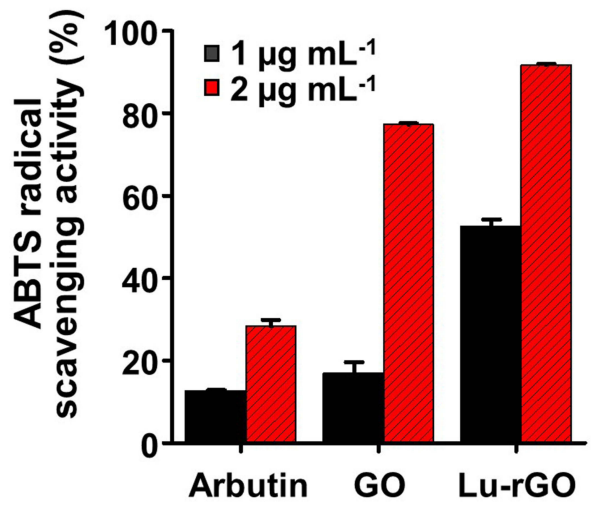

D

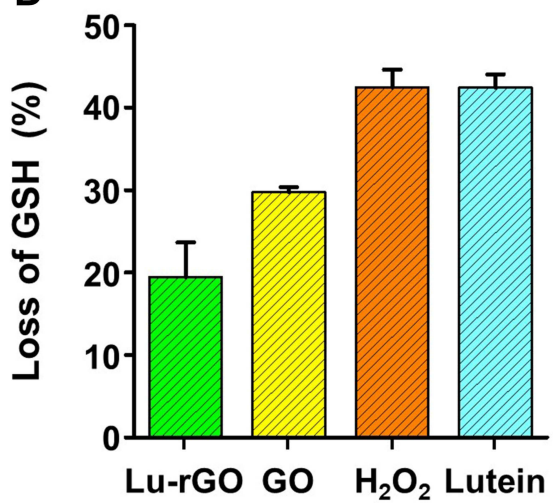

Figure 5 Evaluation of antioxidant activity with radical species. (A and B) ABTS radical scavenging activity of GO and the Lu-rGO complex for each concentration range $\left(1-2 \mu \mathrm{g} \mathrm{mL}^{-1}\right.$ ) compared with the untreated control groups. (C) DPPH radical scavenging activity of GO and the Lu-rGO complex for each concentration range $\left(10-20 \mu \mathrm{mL}^{-1}\right)$ compared with the untreated control groups. (D) Protection activity of the Lu-rGO complex against $\mathrm{GSH}$ oxidation by $\mathrm{H}_{2} \mathrm{O}_{2}$. Abbreviations: ABTS, 2.2'-Azino-bis(3-ethylbenzothiazoline-6-sulfonic acid); DPPH, 2.2-Diphenyl-I-picrylhydrazyl; $\mathrm{GSH}$, glutathione; $\mathrm{H}_{2} \mathrm{O}_{2}$, Hydrogen peroxide.

GSH is a major endogenous antioxidant of eukaryotic cells, and its levels of depletion and consumption are commonly used as reliable indicators for oxidative stress. ${ }^{64,68-70}$ Under such conditions, GSH is converted from a reduced state to its oxidized form (GSH disulfide [GSSG]), particularly by the reduction in GSH levels via oxidation or reaction with thiol groups. Therefore, GSH can neutralize ROS, hydrogen peroxide $\left(\mathrm{H}_{2} \mathrm{O}_{2}\right)$, hydroxyl radicals $(\mathrm{OH})$, superoxide anions $\left(\mathrm{O}_{2}\right)$, and other organic radicals. Hence, cellular oxidative stress and the main mechanism of the antioxidant system can be determined using GSH concentrations. As shown in Figure 5D, this study assessed antioxidant activity using a cell-free GSH oxidation assay. Surprisingly, the oxidation of GSH (ie, the loss of GSH) is reflected in the levels at the same concentration of lutein (42.40\%), GO (29.72\%), 1-M $\mathrm{H}_{2} \mathrm{O}_{2}$ $(42.45 \%)$, and the Lu-rGO complex (19.46\%). A significant reduction in thiol groups by the $\mathrm{Lu}-\mathrm{rGO}$ complex was demonstrated when quantifying the concentration of thiol groups in samples containing GSH using Ellman's reagent (DTNB). Similarly, as observed in Figures $5 \mathrm{~B}$ and $\mathrm{C}$, higher levels of antioxidant activity were exhibited by the Lu-rGO complex compared with the lutein and GO treatments alone. This clearly demonstrates our main scheme for exploiting the antioxidant ability of lutein in combination with an rGO nanocarrier.

It was reported in a previous study that the antioxidant activity of GO is relatively weak, and in particular, the activity of the $\mathrm{H}$-donor antioxidant is lower than that of rGO despite the possession of more hydroxyls. ${ }^{64}$ Therefore, the higher antioxidant activity exhibited by the $\mathrm{Lu}-\mathrm{rGO}$ complex could be attributed to the higher $\mathrm{OH}$ radical scavenging ability of $\mathrm{rGO}$ compared with $\mathrm{GO}$, which was formed spontaneously in the complexation process. Therefore, the Lu-rGO complex can be considered to function as an efficient nanocarrier. It is suggested that the overall antioxidant activity of the $\mathrm{Lu}-\mathrm{rGO}$ complex is related to the network and the main active sites of 
graphene as well to the oxygen-containing functional group of the Lu-rGO complex. The most acceptable model for the $\mathrm{GO}$ structure places the $\mathrm{OH}$ group at the basal planar site. Here, topical $\mathrm{sp}^{3}$ sites that do not provide the neighbor-conjugated structure required for radical resonance stabilization can be used for the oxidation of $\mathrm{C}=\mathrm{C}$ bonds. As the antioxidant activity of these basal $\mathrm{OH}$ groups of GO are expected to be weak, the primary radical scavenging sites can be related to the primitive $\mathrm{sp}^{2}$-carbon domains acting through adduct formation or electron transfer. ${ }^{64,71}$ Extensive research has been conducted on the blue light filtering and antioxidant abilities of lutein; however, its application to date has been limited by its instability and low water solubility. To address these issues, this study successfully synthesized the Lu-rGO complex. The complex demonstrated good dispersibility due to the increase of the peptide in the amide group, which was beneficial for the integration with lutein. These results confirm that the proposed strategy further maximized the antioxidant efficacy of lutein in the form of the complexation (ie, Lu-rGO) and demonstrated superior performance to the treatment with lutein alone (see Figures $\underline{\mathrm{S} 3}$ and 4). ${ }^{4}$ The comprehensive assessment conducted in this paper demonstrated an effective delivery system that enhanced the solubility and stability of lutein as a cellular antioxidant during complexation and promoted the entrapped potential capability of lutein.

\section{ROS-Inhibition Effect by GO and the Lu- rGO Complex in ARPE-19 Cells}

The Lu-rGO complex with ROS-inhibiting activity presented in this study could be considered as a new molecule for protecting cells or tissues from oxidative stress. As it is accepted that blue light increases the production of free radicals (ie, ROS), it is beneficial to confirm the antioxidant effect in human RPE cells to determine the extent of biochemical interactions under blue light irradiation. Therefore, a blue light source from an OLED (more information is available in Figure S5 and Table S1) device was placed at the bottom of a cell culture well-plate where it stimulated the cultured cells by upward emission (see Figure 6A for a schematic description). A model system was established by culturing ARPE-19 cells to investigate the protection offered by the $\mathrm{Lu}-\mathrm{rGO}$ complex in terms of cell viability and ROS under conditions of blue light exposure (Figures 6B and $\mathrm{C}$ ). In this experimental setup, oxidative stress from the ARPE-19 cells seeded in well plates was detected via blue light stimulation (ie, absorbance at a wavelength of $\sim 450 \mathrm{~nm}$ ).

In accordance with Figure 6D, the viability of the APRE-19 cells treated with the Lu-rGO complex was analyzed. No significant effect was observed in the concentration range of $1-2 \mu \mathrm{g} \mathrm{mL}^{-1}$ treated during the period, although a slightly decreasing trend was evident at the relatively high concentration of $4 \mu \mathrm{g} \mathrm{mL}^{-1}$ within the treatment time. The concentration of the $\mathrm{Lu}-\mathrm{rGO}$ complex was determined using this control experiment, and a reduced concentration of $1 \mu \mathrm{g} \mathrm{mL}^{-1}$ was used in the subsequent test.

Next, estimations were made of the ROS and oxidative stress levels on the ARPE-19 cells stimulated by blue light irradiation. When the oxidative stress inhibition effect was analyzed according to treatment with the Lu-rGO complex, the intracellular ROS was quantified using a general oxidative stress indicator (CM- $\mathrm{H}_{2}$ DCFDA). When dichlorofluorescein diacetate (DCFDA) passively enters a cell, the two ester bonds in its structure are broken. Consequently, $\mathrm{H}_{2} \mathrm{DCF}$ can be produced and accumulated by ROS in cells. The cells are then oxidized, which is represented as highly fluorescent DCF. As can be seen in the left graph of Figure 6E, the OLED blue light caused an approximate 1.5 -fold increase in ROS levels, and the presence of the Lu-rGO complex was effectively involved in the consistent decrease of the ROS $(\sim 30 \%)$ in the ARPE19 cells.

Increasing levels of ROS can cause changes in the lysosome content. Because lysosomes are organelles that contain cell-digestive enzymes, they can degrade substances entering cells or remove damaged organelles, mainly via the processes of endocytosis or phagocytosis. Specifically, lysosomes are involved in maintaining intracellular homeostasis by cellular autophagy in cases of damaged organelles or those with low nutrient content, ie, lysosomes partially degrade or digest cells affected by oxidation, senescence, or ROS. ${ }^{27,72,73}$ Therefore, as depicted in the right-hand graph of Figure 6E, the lysosome content in the cells were measured using a fluorescent probe (LysoTracker Green DND-26) (Figure S6). When compared with the normal control group $(10.96 \%)$, there was a significant increase in cellular lysosome content $(64.37 \%)$ following blue light exposure, while there was a slight decrease in the cells treated with the Lu-rGO complex $(51.88 \%)$. Therefore, this result indirectly signifies that lysosome-dependent autophagy regulation can be partially achieved with the assistance 
A

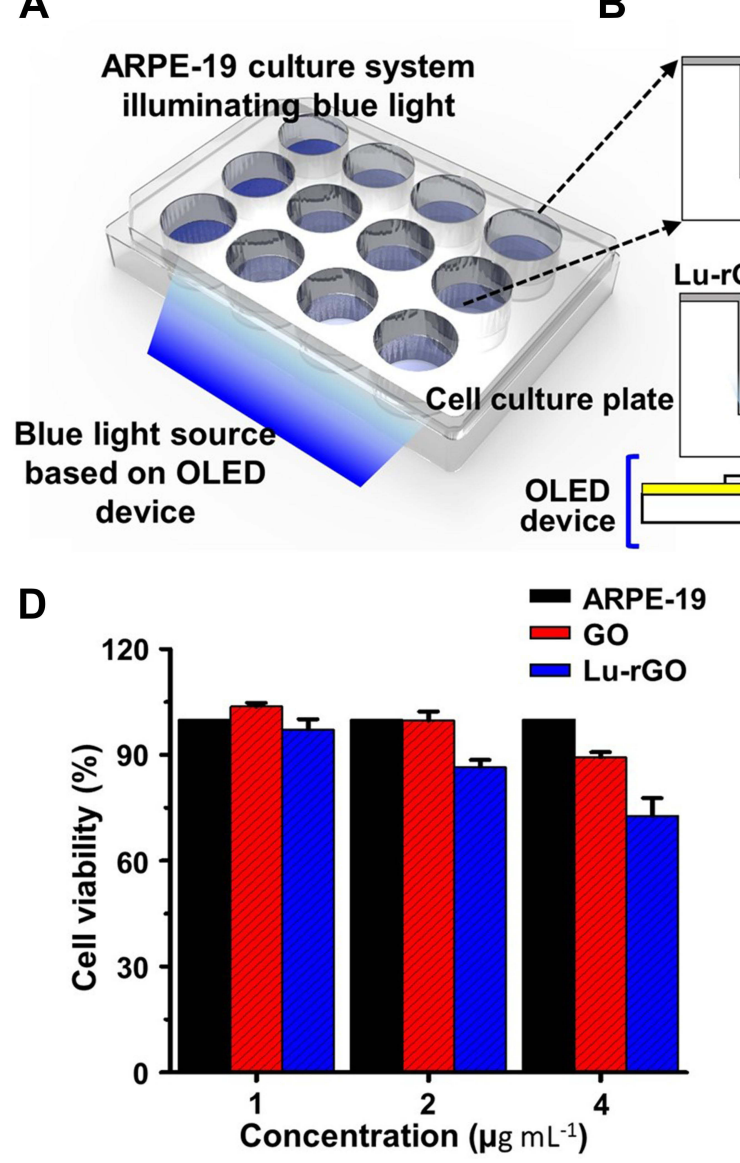

C

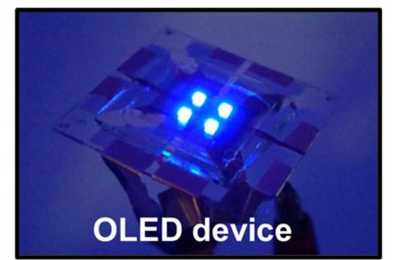

OLED device

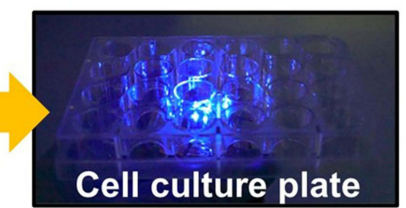

Figure 6 Blue light-induced oxidative stress in ARPE-19 cells and the ROS-inhibition effect of the Lu-rGO complex. (A and B) OLED blue light source positioned at the bottom of the cell culture well-plate for upward stimulation of the cultured cells. (C) Digital image of the OLED device (top) in the well-plate. (D) Cell viability of GO and the Lu-rGO complex according to each concentration evaluated for $48 \mathrm{~h}$ by WST-I assay (ARPE-I9: control, GO: GO-treated-cells, and Lu-rGO: Lu-rGO complex-treated cells). (E) The inhibitory effect of ROS production of the Lu-rGO complex in ARPE-19 cells exposed to blue light as analyzed by DCFDA fluorescence assay (left) and the change in lysosome content of the Lu-rGO complex in ARPE-19 cells under blue light exposure as measured by DND-26 staining (right).

Abbreviations: ROS, reactive oxygen species; OLED, organic light-emitting diode; DCFDA, CM- $\mathrm{H}_{2}$ DCFDA; DND-26, LysoTracker Green DND-26; ARPE-19, untreated control; Blue light, blue light-irradiated cells; BL-Lu-rGO, blue light-irradiated cells treated with the Lu-rGO complex.

of the $\mathrm{Lu}-\mathrm{rGO}$ complex by reducing excessive increases in lysosomes to maintain cellular homeostasis.

Figure 7A provides additional information and presents summarized fluorescent micrographs for the detection of ROS on the cultured ARPE-19 cells following blue light irradiation and treatment with the Lu-rGO complex. When the cells were irradiated by blue light, the strong green fluorescence of DCF was observed. However, when the cells were treated with the Lu-rGO complex, there was a marked decrease in the intensity of fluorescence expression. The differences were clarified by quantifying the intensity of the fluorescence (Figures 7B and C). The results suggest that the low-level cellular presence of the Lu-rGO complex $\left(1 \mu \mathrm{g} \mathrm{mL}{ }^{-1}\right)$ can reduce ROS levels, thereby protecting cells from blue light exposure. This finding correlates with the data in Figure $6 \mathrm{E}$.
Additionally, from the results, it is suggested that the activity of ROS was clearly suppressed by the complexation of phytochemical lutein with the rGO nanocarrier, which indicates effective cytoprotective properties and a related antioxidant effect. The collective results presented in Figure 7 indicate that the Lu-rGO complex inhibits blue light-induced intracellular ROS production and oxidative stress and offers some degree of cellular protection. This offers potential for new therapeutic applications for retinal diseases (eg, AMD), which could involve the strategic use of nanocarriers in drug-delivery systems, diagnostic therapies, and chemotherapy.

In principle, the mitochondrial electron transport chain is a major source of intracellular ROS. ${ }^{74,75}$ Moreover, in the respiratory chain, blue light is absorbed directly by molecules, such as flavin and cytochrome oxidase, which 
A
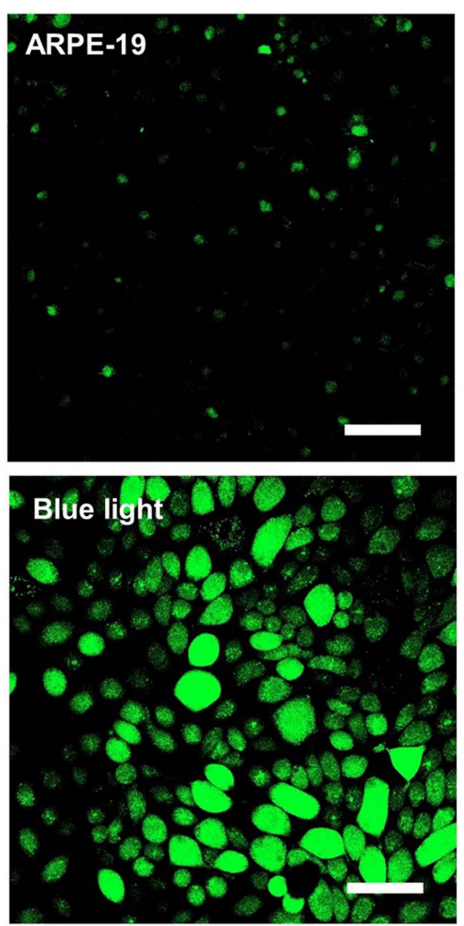
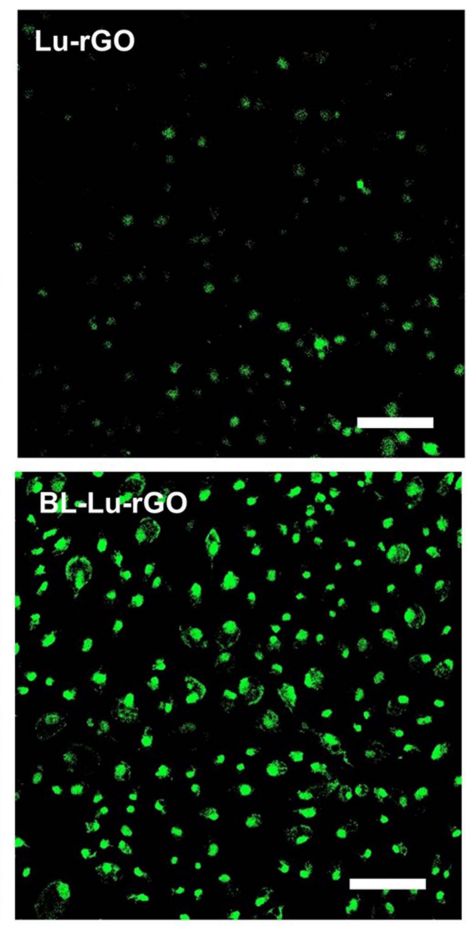

\section{B}
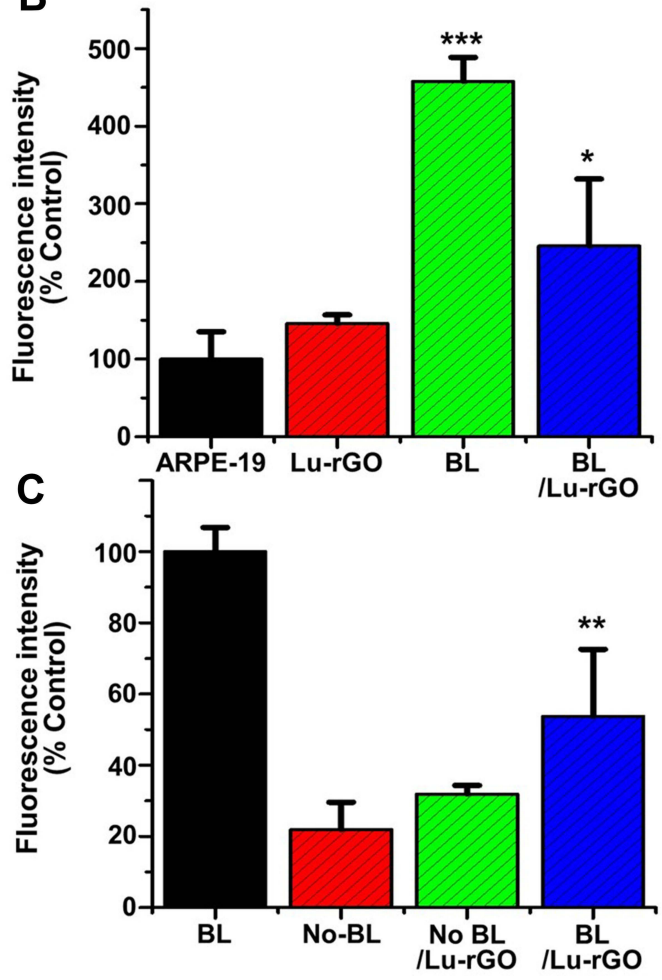

Figure 7 Fluorescence micrographs of intracellular ROS on ARPE-19 cells irradiated with blue light in the presence or absence of the Lu-rGO complex. (A) Confocal micrographs of ARPE-19 cells (untreated control), Lu-rGO complex-treated cells (Lu-rGO), blue light-irradiated cells (blue light), and blue light-irradiated cells treated with the Lu-rGO complex (BL-Lu-rGO). The scale bars are $100 \mu \mathrm{m}$. (B) Fluorescence quantification values for untreated ARPE-19 cells. (C) Fluorescence quantification values for the blue light-irradiated cells $(* \mathrm{p}<0.05, * *<0.0 \mathrm{I}, * * *<0.00 \mathrm{I})$.

Abbreviations: ARPE-1 9 cells, untreated control; Lu-rGO, Lu-rGO complex-treated cells; BL, blue light-irradiated cells; BL/Lu-rGO, blue light-irradiated cells treated with the Lu-rGO complex.

ultimately increases both cellular ROS and oxidative stress. $^{76-79}$ The process of mitochondrial redistribution with morphological changes in ARPE-19 cells under blue light irradiation has been reported previously; the mitochondria of RPE cells irradiated at a wavelength of $\sim 400$ nm were observed to be denatured and low level in distribution and were observed to be prominent only in the perinuclear region. ${ }^{80}$ The same condition was reported in a similar study in which a generation of long and large mitochondria exhibited a reduction in their membrane potential for ARPE-19 cells. The experiment found that after blue light exposure, the majority of the mitochondria were located in the area surrounding the entire nucleus in an abnormally elongated form. ${ }^{81}$ Based on these previous studies, it is clear that blue light exposure affects cells by causing oxidative stress and cellular damage (Figure 6E). Generally, oxidative stress due to an imbalance of redox status initiates changes in the biological structure of DNA, lipids, and proteins. As such byproducts present in retinal epithelial cells and the occurrence of retinal disease are closely linked, the results presented in this study strongly suggest that the Lu-rGO complex is beneficial for protecting cells and preventing mitochondrial damage by its inhibition of both ROS and oxidative stress due to blue light exposure. It has little efficacy in the present luteinalone treatment. Moreover, only a few studies have been conducted using different approaches such as nanoemulsifying, nanostructured lipid carriers, and nanoliposome. While our proposed nanosystem (an anti-blue light luteinnanocarrier with $\mathrm{GO}$ ) is advantageous to facilitate the lutein using GO nanocarrier. In particular, the simple application of aqueous composites of the Lu-rGO complex provides significant biocompatibility with unique biologically active interfaces that promote biomolecular binding of various surface functional groups due to the excellent chemical and physical properties of carbon nanomaterials. $^{82,83}$ In addition, the proposed graphenebased nanocarriers offer a high level of oxidation protection in the form of planar nanosheets or encapsulation shells as they function as physical barriers to chemical antioxidants and oxidant transport. Therefore, an appropriate concentration of the Lu-rGO complex offers 
considerable biocompatibility, which could be applied to bio-interfaces in the field of tissue engineering. ${ }^{84}$

\section{Conclusion}

In summary, we developed a simple synthetic method for producing an antioxidant-delivery material to protect and control the release of lutein and to improve its absorption and bioavailability. The proposed scheme enhanced the high solubility and stability of the bioactive agent while preventing unwanted molecular interactions within the delivery system. Furthermore, the spontaneous reduction of lutein-contacted GO during the complexation process and the subsequent activity of antioxidants offers significant potential for practical applications and exhibit several unique features compared with previously reported strategies. These can be summarized, as follows: i) The scheme is eco-friendly, safe, and uses no synthetic chemicals or toxic agents in the reduction process. Additionally, it produces no hazardous waste. ii) As no complex procedures are required, the scheme is simple and cost effective. iii) A simultaneous reduction of GO and antioxidant functionalization by lutein was achieved. Therefore, GO functional groups can be removed efficiently and expanded easily, and the obtained the Lu-rGO complex can be dispersed in other solvents. iv) The Lu-rGO complex can inhibit blue light-induced ROS and oxidative stress, protecting RPE cells and potentially preventing retinal-related diseases. We believe conclusively that the Lu-rGO complex presented herein has excellent potential for biomedical application in various processes ranging from retinal cell imaging to drug delivery. It could be particularly beneficial for the treatment and prevention of retinalrelated diseases, including AMD, which is induced by blue light and oxidative stress. It is anticipated that the proposed scheme will be developed as a therapeutic strategy. ${ }^{85,86}$

\section{Data Sharing Statement}

Supplementary Information is available online: Electroluminescence properties of the provided OLED devices (Table S1); XPS survey spectra of (A) graphene oxide (B) Lu-Rgo (Figure S1); ABTS radicals scavenging activity of GO and Lu-rGO complex by concentration (Figure S2); ABTS radical scavenging activity of LurGO complex, GO and Lutein (Figure S3); DPPH radical scavenging activity of Lu-rGO complex, GO and Lutein (Figure S4); The current density and luminance (a), external quantum efficiency (b), and color coordinates (c) of
OLED-based light source (Figure S5); Changes of lysosome contents in the ARPE-19 cells (Figure S6).

\section{Consent for Publication}

All authors agree to publish this research.

\section{Acknowledgments}

We gratefully acknowledge the supports from the National Research Foundation (NRF) of Korea under the auspices of the Ministry of Science and ICT, Republic of Korea.

\section{Author Contributions}

All authors made a significant contribution to the work reported, whether that is in the conception, study design, execution, acquisition of data, analysis and interpretation, or in all these areas; took part in drafting, revising or critically reviewing the article; gave final approval of the version to be published; have agreed on the journal to which the article has been submitted; and agree to be accountable for all aspects of the work.

\section{Funding}

This work was supported by the National Research Foundation (NRF) of Korea under the auspices of the Ministry of Science and ICT, Republic of Korea (Grant No. NRF2019R1A6A3A01095293, NRF-2020R1F1A1077033, and NRF-2021R1A5A1032937).

\section{Disclosure}

The authors declare no conflicts of interest.

\section{References}

1. Sajilata MG, Singhal RS, Kamat MY. The carotenoid pigment zeaxanthin - a review. Compr Rev Food Sci Food Saf. 2008;7:29-49. doi:10.1111/j.1541-4337.2007.00028.x

2. Jiao Y, Zheng X, Chang Y, Li D, Sun X, Liu X. Zein-derived peptides as nanocarriers to increase the water solubility and stability of lutein. Food Funct. 2018;9:117-123. doi:10.1039/C7FO01652B

3. Kijlstra A, Tian Y, Kelly ER, Berendschot TT. Lutein: more than just a filter for blue light. Prog Retin Eye Res. 2012;31:303-315. doi:10.1016/j.preteyeres.2012.03.002

4. Li LH, Lee JC, Leung HH, Lam WC, Fu Z, Lo ACY. Lutein supplementation for eye diseases. Nutrients. 2020;12:1721. doi:10.3390/ nu12061721

5. Nwachukwu ID, Udenigwe CC, Aluko RE. Lutein and zeaxanthin: production technology, bioavailability, mechanisms of action, visual function, and health claim status. Trends Food Sci Technol. 2016;49:74-84. doi:10.1016/j.tifs.2015.12.005

6. Rodriguez-Concepcion M, Avalos J, Bonet ML, et al. A global perspective on carotenoids: metabolism, biotechnology, and benefits for nutrition and health. Prog Lipid Res. 2018;70:62-93. doi:10.1016/j. plipres.2018.04.004 
7. Liguori N, Xu P, van Stokkum IHM, et al. Different carotenoid conformations have distinct functions in light-harvesting regulation in plants. Nat Commun. 2017;8:1-9. doi:10.1038/s41467-017-02239-z

8. Krinsky NI, Landrum JT, Bone RA. Biologic mechanisms of the protective role of lutein and zeaxanthin in the eye. Annu Rev Nutr. 2003;23:171-201. doi:10.1146/annurev.nutr.23.011702.073307

9. Zhang C, Wang $\mathrm{X}$, Du J, Gu Z, Zhao Y. Reactive oxygen species-regulating strategies based on nanomaterials for disease treatment. Adv Sci. 2021;8:2002797. doi:10.1002/advs.202002797

10. Birch DG, Liang FQ. Age-related macular degeneration: a target for nanotechnology derived medicines. Int $J$ Nanomedicine. 2007;2 (1):65. doi:10.2147/nano.2007.2.1.65

11. Kamoshita M, Toda E, Osada $\mathrm{H}$, et al. Lutein acts via multiple antioxidant pathways in the photo-stressed retina. Sci Rep. 2016;6:1-10. doi:10.1038/srep30226

12. Ratnayake K, Payton JL, Lakmal OH, Karunarathne A. Blue light excited retinal intercepts cellular signaling. Sci Rep. 2018;8:10207. doi:10.1038/s41598-018-28254-8

13. Gehrs KM, Anderson DH, Johnson LV, Hageman GS. Age-related macular degeneration-emerging pathogenetic and therapeutic concepts. Ann Med. 2006;38:450-471. doi:10.1080/ 07853890600946724

14. Klein R, Chou C, Klein BE, Zhang X, Meuer SM, Saaddine JB. Prevalence of age-related macular degeneration in the US population. Arch Ophthalmol. 2011;129:75-80. doi:10.1001/archophthalmol.2010.318

15. Golestaneh N, Chu Y, Xiao Y, Stoleru GL, Theos AC. Dysfunctional autophagy in RPE, a contributing factor in age-related macular degeneration. Cell Death Dis. 2018;8:e2537. doi:10.1038/ cddis. 2016.453

16. Fisher CR, Ferrington DA. Perspective on AMD pathobiology: a bioenergetic crisis in the RPE. Invest Ophthalmol Vis Sci. 2018;59:AMD41-AMD47. doi:10.1167/iovs.18-24289

17. Marie M, Bigot K, Angebault C, et al. Light action spectrum on oxidative stress and mitochondrial damage in A2E-loaded retinal pigment epithelium cells. Cell Death Dis. 2018;9:1-13. doi:10.1038/s41419-018-0331-5

18. Margrain TH, Boulton M, Marshall J, Sliney DH. Do blue light filters confer protection against age-related macular degeneration? Prog Retin Eye Res. 2004;23:523-531. doi:10.1016/j. preteyeres.2004.05.001

19. Zhu X, Zou H, Yu Y, Sun Q, Zhao N. Comparison of blue light-filtering IOLs and UV light-filtering IOLs for cataract surgery: a meta-analysis. PLoS One. 2012;7:e33013. doi:10.1371/journal. pone. 0033013

20. Brown EE, DeWeerd AJ, Ildefonso CJ, Lewin AS, Ash JD. Mitochondrial oxidative stress in the retinal pigment epithelium (RPE) led to metabolic dysfunction in both the RPE and retinal photoreceptors. Redox Biol. 2019;24:101201. doi:10.1016/j.redox.2019.101201

21. Datta S, Cano M, Ebrahimi K, Wang L, Handa JT. The impact of oxidative stress and inflammation on RPE degeneration in non-neovascular AMD. Prog Retin Eye Res. 2017;60:201-218. doi:10.1016/j.preteyeres.2017.03.002

22. Beatty S, Koh H, Phil M, Henson D, Boulton M. The role of oxidative stress in the pathogenesis of age-related macular degeneration. Surv Ophthalmol. 2000;45:115-134. doi:10.1016/ s0039-6257(00)00140-5

23. Chae SY, Park SY, Park G. Lutein protects human retinal pigment epithelial cells from oxidative stress-induced cellular senescence. $\mathrm{Mol}$ Med Rep. 2018;18:5182-5190. doi:10.3892/mmr.2018.9538

24. Sanad MF, Shalan AE, Bazid SM, et al. A graphene gold nanocomposite-based 5-FU drug and the enhancement of the MCF-7 cell line treatment. RSC Adv. 2019;9:31021-31029. doi:10.1039/c9ra05669f
25. Chae SY, Park SY, Park JO, Lee KJ, Park G. Gardenia jasminoides extract-capped gold nanoparticles reverse hydrogen peroxide-induced premature senescence. J Photochem Photobiol B. 2016;164:204-211. doi:10.1016/j.jphotobiol.2016.09.033

26. BarathManiKanth S, Kalishwaralal K, Sriram M, et al. Anti-oxidant effect of gold nanoparticles restrains hyperglycemic conditions in diabetic mice. J Nanobiotechnology. 2010;8:1-15. doi:10.1186/ 1477-3155-8-16

27. Chae SY, Shrestha KR, Jeong S, Park G, Yoo SY. Bioinspired RGD-engineered bacteriophage nanofiber cues against oxidative stress. Biomacromolecules. 2019;20:3658-3671. doi:10.1021/acs. biomac. $9 \mathrm{~b} 00640$

28. Schieber M, Chandel NS. ROS function in redox signaling and oxidative stress. Curr Biol. 2014;24:R453-R462. doi:10.1016/j. cub.2014.03.034

29. Jacobson MD. Reactive oxygen species and programmed cell death. Trends Biochem Sci. 1996;21:83-86. doi:10.1016/S0968-0004(96) 20008-8

30. Kamata H, Honda S, Maeda S, Chang L, Hirata H, Karin M. Reactive oxygen species promote $\mathrm{TNF} \alpha$-induced death and sustained JNK activation by inhibiting MAP kinase phosphatases. Cell. 2005;120:649-661. doi:10.1016/j.cell.2004.12.041

31. Sies H, Jones DP. Reactive oxygen species (ROS) as pleiotropic physiological signaling agents. Nat Rev Mol Cell Biol. 2020;21:363-383. doi:10.1038/s41580-020-0230-3

32. Srinivas US, Tan BWQ, Vellayappan BA, Jeyasekharan AD. ROS and the DNA damage response in cancer. Redox Biol. 2019;25:101084. doi:10.1016/j.redox.2018.101084

33. Liang F, Godley BF. Oxidative stress-induced mitochondrial DNA damage in human retinal pigment epithelial cells: a possible mechanism for RPE aging and age-related macular degeneration. Exp Eye Res. 2003;76:397-403. doi:10.1016/s0014-4835(03)00023-x

34. Núñez-álvarez C, Suárez-Barrio C, Del Olmo Aguado S, Osborne NN. Blue light negatively affects the survival of ARPE 19 cells through an action on their mitochondria and blunted by red light. Acta Ophthalmol. 2019;97:e103-e115. doi:10.1111/aos.13812

35. Lockwood DB, Wataha JC, Lewis JB, Tseng WY, Messer RL, Hsu SD. Blue light generates reactive oxygen species (ROS) differentially in tumor vs. normal epithelial cells. Dent Mater. 2005;21:683-688. doi:10.1016/j.dental.2004.07.022

36. El-Esawi M, Arthaut L, Jourdan N, et al. Blue-light induced biosynthesis of ROS contributes to the signaling mechanism of Arabidopsis cryptochrome. Sci Rep. 2017;7:1-9. doi:10.1038/ s41598-017-13832-z

37. Fleury C, Mignotte B, Vayssière J. Mitochondrial reactive oxygen species in cell death signaling. Biochimie. 2002;84:131-141. doi:10.1016/s0300-9084(02)01369-x

38. Ryter SW, Kim HP, Hoetzel A, et al. Mechanisms of cell death in oxidative stress. Antioxid Redox Signal. 2007;9:49-89. doi:10.1089/ ars.2007.9.49

39. Stankovich S, Dikin DA, Dommett GH, et al. Graphene-based composite materials. Nature. 2006;442:282-286. doi:10.1038/nature04969

40. Dikin DA, Stankovich S, Zimney EJ, et al. Preparation and characterization of graphene oxide paper. Nature. 2007;448:457-460. doi:10.1038/nature06016

41. Yi D, Jeon S, Hong SW. Selectively patterned regrowth of bilayer graphene for the self-Integrated electronics by sequential chemical vapor deposition. ACS Appl Mater Interfaces. 2018;10:40014. doi:10.1021/acsami.8b11902

42. Zielińska-Górska M, Hotowy A, Wierzbicki M, et al. Graphene oxide nanofilm and the addition of 1-glutamine can promote development of embryonic muscle cells. $J$ Nanobiotechnology. 2020;18:1-17. doi:10.1186/s12951-020-00636-z 
43. Kim RH, Bae MH, Kim DG, et al. Stretchable, Transparent graphene interconnects for arrays of microscale inorganic light emitting diodes on rubber substrates. Nano Lett. 2011;11:3881-3886. doi:10.1021/ nl202000u

44. Jeon S, Lee J, Park R, et al. Graphene Templated DNA arrays and biotin-streptavidin sensitive bio-transistors patterned by dynamic self-assembly of polymer. Nanomaterials. 2020;10:1468. doi:10.3390/ nano10081468

45. Hong SW, Du F, Lan W, Kim S, Kim H, Rogers JA. Monolithic integration of arrays of single-walled carbon nanotubes and sheets of graphene. Adv Mater. 2011;23:3821-3826. doi:10.1002/adma.201101955

46. Sidhureddy B, Thiruppathi AR, Chen A. From graphite to interconnected reduced graphene oxide: one-pot synthesis and supercapacitor application. Chem Commun. 2017;53:7828-7831. doi:10.1039/C7CC03060F

47. Bhattacharya G, Sas S, Wadhwa S, Mathur A, McLaughlin J, Roy SS. Aloe vera assisted facile green synthesis of reduced graphene oxide for electrochemical and dye removal applications. RSC $A d v$. 2017;7:26680-26688. doi:10.1039/C7RA02828H

48. Lee JH, Shin YC, Jin OS, et al. Reduced graphene oxide-coated hydroxyapatite composites stimulate spontaneous osteogenic differentiation of human mesenchymal stem cells. Nanoscale. 2015;7:11642-11651. doi:10.1039/C5NR01580D

49. Kang SH, Shin YC, Hwang EY, et al. Engineered "coffee-rings" of reduced graphene oxide as ultrathin contact guidance to enable patterning of living cells. Mater Horiz. 2019;6:1066-1079. doi:10.1039/ C8MH01381K

50. Fernández-Merino MJ, Guardia L, Paredes JI, et al. Vitamin C is an ideal substitute for hydrazine in the reduction of graphene oxide suspensions. J Phys Chem C. 2010;114:6426-6432. doi:10.1021/ jp100603h

51. Qiu Y, Wang Z, Owens AC, et al. Antioxidant chemistry of graphene-based materials and its role in oxidation protection technology. Nanoscale. 2014;6:11744-11755. doi:10.1039/ C4NR03275F

52. Yin J, Lao F, Fu PP, et al. The scavenging of reactive oxygen species and the potential for cell protection by functionalized fullerene materials. Biomaterials. 2009;30:611-621. doi:10.1016/j. biomaterials.2008.09.061

53. Perreault F, De Faria AF, Nejati S, Elimelech M. Antimicrobial properties of graphene oxide nanosheets: why size matters. ACS Nano. 2015;9:7226-7236. doi:10.1021/acsnano.5b02067

54. Vecitis CD, Zodrow KR, Kang S, Elimelech M. Electronic-structuredependent bacterial cytotoxicity of single-walled carbon nanotubes. ACS Nano. 2010;4:5471-5479. doi:10.1021/nn101558x

55. Pasquini LM, Sekol RC, Taylor AD, Pfefferle LD, Zimmerman JB. Realizing comparable oxidative and cytotoxic potential of single-and multiwalled carbon nanotubes through annealing. Environ Sci Technol. 2013;47:8775-8783. doi:10.1021/es401786s

56. Kuznetsov AV, Kehrer I, Kozlov AV, et al. Mitochondrial ROS production under cellular stress: comparison of different detection methods. Anal Bioanal Chem. 2011;400:2383-2390. doi:10.1007/ s00216-011-4764-2

57. Strauss O. The retinal pigment epithelium in visual function. Physiol Rev. 2005;85:845-881. doi:10.1152/physrev.00021.2004

58. Mehta S. Age-related macular degeneration. Prim Care. 2015;42:377-391. doi:10.1016/j.pop.2015.05.009

59. Yang J, Yu Z, Cheng S, et al. Graphene oxide-based nanomaterials: an insight into retinal prosthesis. Int $J$ Mol Sci. 2020;21:2957. doi:10.3390/ijms21082957

60. Ferrari AC, Meyer JC, Scardaci V, et al. Raman spectrum of graphene and graphene layers. Phys Rev Lett. 2006;97(18):187401. doi:10.1103/PhysRevLett.97.187401

61. Xavier DB, Susana AG, Cristin B, et al. Raman spectroscopy for the study of reduction mechanisms and optimization of conductivity in graphene oxide thin films. J Mater Chem C. 2013;1:6905-6912. doi:10.1039/C3TC31124D
62. Shin MC, Kang MS, Park R, Chae SY, Han DW, Hong SW. Differential cellular interactions and responses to ultrathin micropatterned graphene oxide arrays with or without ordered in turn RGD peptide films. Appl Surf Sci. 2021;561:150115. doi:10.1021/ acsami.8b11902

63. Shih C, Vijayaraghavan A, Krishnan R, et al. Bi-and trilayer graphene solutions. Nat Nanotechnol. 2011;6:439. doi:10.1038/ NNANO.2011.94

64. Qiu Y, Wang Z, Owens AC, et al. Antioxidant chemistry of graphene-based materials and its role in oxidation protection technology. Nanoscale. 2014;6:11744. doi:10.1039/C4NR03275F

65. Baali N, Khecha A, Bensouici A, Speranza G, Hamdouni N. Assessment of Antioxidant Activity of Pure Graphene Oxide (GO) and ZnO-Decorated Reduced Graphene Oxide (rGO) Using DPPH Radical and H2O2 Scavenging Assays. C-J Carbon Res. 2019;5:75. doi: $10.3390 / \mathrm{c} 5040075$

66. Sanna V, Pala N, Dessì G, et al. Single-step green synthesis and characterization of gold-conjugated polyphenol nanoparticles with antioxidant and biological activities. Int $J$ Nanomedicine. 2014;9:4935. doi:10.2147/IJN.S70648

67. Re R, Pellegrini N, Proteggente A, Pannala A, Yang M, Rice-Evans C. Antioxidant activity applying an improved ABTS radical cation decolorization assay. Free Radic Biol Med. 1999;26:1231-1237. doi:10.1016/S0891-5849(98)00315-3

68. Limón-Pacheco J, Gonsebatt ME. The role of antioxidants and antioxidant-related enzymes in protective responses to environmentally induced oxidative stress. Mutat Res Genet Toxicol Environ Mutagen. 2009;674:137-147. doi:10.1016/j.mrgentox.2008.09.015

69. Valko M, Leibfritz D, Moncol J, Cronin MT, Mazur M, Telser J. Free radicals and antioxidants in normal physiological functions and human disease. Int $J$ Biochem Cell Biol. 2007;39:44-84. doi:10.1016/j.biocel.2006.07.001

70. Ballatori N, Krance SM, Notenboom S, Shi S, Tieu K, Hammond CL. Glutathione dysregulation and the etiology and progression of human diseases. Biol Chem. 2009;390:191-214. doi:10.1515/BC.2009.033

71. Bitner BR, Marcano DC, Berlin JM, et al. Antioxidant carbon particles improve cerebrovascular dysfunction following traumatic brain injury. ACS Nano. 2012;6:8007-8014. doi:10.1021/nn302615f

72. Huang D, Zhou H, Gao J. Nanoparticles modulate autophagic effect in a dispersity-dependent manner. Sci Rep. 2015;5:14361. doi:10.1038/srep14361

73. Ma X, Wu Y, Jin S, et al. Gold nanoparticles induce autophagosome accumulation through size-dependent nanoparticle uptake and lysosome impairment. ACS Nano. 2011;5:8629-8639. doi:10.1021/ nn202155y

74. Cai J, Nelson KC, Wu M, Sternberg P, Jones DP. Oxidative damage and protection of the RPE. Prog Retin Eye Res. 2000;19:205-221. doi:10.1016/S1350-9462(99)00009-9

75. Murphy MP. How mitochondria produce reactive oxygen species. Biochem J. 2009;417:1-13. doi:10.1042/BJ20081386

76. Lascaratos G, Ji D, Wood JP, Osborne NN. Visible light affects mitochondrial function and induces neuronal death in retinal cell cultures. Vision Res. 2007;47:1191-1201. doi:10.1016/j.visres.2006.12.014

77. Miyata S, Miyaji H, Kawasaki H, et al. Antimicrobial photodynamic activity and cytocompatibility of Au25 (Capt) 18 clusters photoexcited by blue LED light irradiation. Int $J$ Nanomedicine. 2017;12:2703. doi:10.2147/IJN.S82061

78. Nakanishi-Ueda T, Majima HJ, Watanabe K, et al. Blue LED light exposure develops intracellular reactive oxygen species, lipid peroxidation, and subsequent cellular injuries in cultured bovine retinal pigment epithelial cells. Free Radic Res. 2013;47:774-780. doi:10.3109/10715762.2013.829570

79. Ayala Kingt EG, Brooks DG, Murphy MP, Dunaief JL. Mitochondria-derived Reactive Oxygen Species Mediate Blue Light-induced Death of Retinal Pigment Epithelial Cells. Photochem Photobiol. 2004;79:470475. doi:10.1562/le-03-17.1 
80. Youn H, Chou BR, Cullen AP, Sivak JG. Effects of 400 nm, 420 nm, and $435.8 \mathrm{~nm}$ radiations on cultured human retinal pigment epithelial cells. J Photochem Photobiol B. 2009;95:64-70. doi:10.1016/j. jphotobiol.2009.01.001

81. Roehlecke C, Schaller A, Knels L, Funk RH. The influence of sublethal blue light exposure on human RPE cells. Mol Vis. 2009;15:1929.

82. Shin SR, Li Y, Jang HL, et al. Graphene-based materials for tissue engineering. Adv Drug Deliv Rev. 2016;105:255-274. doi:10.1016/j. addr.2016.03.007

83. Cheng C, Li S, Thomas A, Kotov NA, Haag R. Functional graphene nanomaterials Based architectures: biointeractions, fabrications, and emerging biological applications. Chem Rev. 2017;117:1826-1914. doi:10.1021/acs.chemrev.6b00520
84. Pattnaik S, Swain K, Lin Z. Graphene and graphene-based nanocomposites: biomedical applications and biosafety. J Mater Chem B. 2016;4:7813-7831. doi:10.1039/c6tb02086k

85. Lee J, Kim J, Kim S, Min DH. Biosensors Based on Graphene Oxide and Its Biomedical Application. Adv Drug Deliv Rev. 2016;105:275-287. doi:10.1016/j.addr.2016.06.001

86. Liu J, Cui L, Losic D. Graphene and Graphene Oxide as New Nanocarriers for Drug Delivery Applications. Acta Biomater. 2013;9:9243-9257. doi:10.1016/j.actbio.2013.08.016

\section{Publish your work in this journal}

The International Journal of Nanomedicine is an international, peerreviewed journal focusing on the application of nanotechnology in diagnostics, therapeutics, and drug delivery systems throughout the biomedical field. This journal is indexed on PubMed Central, MedLine, CAS, SciSearch ${ }^{\mathbb{R}}$, Current Contents ${ }^{\mathbb{R}} /$ Clinical Medicine, $^{-}$
Journal Citation Reports/Science Edition, EMBase, Scopus and the Elsevier Bibliographic databases. The manuscript management system is completely online and includes a very quick and fair peer-review system, which is all easy to use. Visit http://www.dovepress.com/ testimonials.php to read real quotes from published authors. 